\title{
Cultural Assimilation, Cultural Diffusion and the Origin of the Wealth of Nations*
}

\author{
Quamrul Ashraf $f^{\dagger} \quad$ Oded Galor
}

April 23, 2007

\begin{abstract}
This research argues that variations in the interplay between cultural assimilation and cultural diffusion have played a significant role in giving rise to differential patterns of economic development across the globe. Societies that were geographically less vulnerable to cultural diffusion, benefited from enhanced assimilation, lower cultural diversity and, thus, more intense accumulation of society-specific human capital, enabling them to flourish in the technological paradigm that characterized the agricultural stage of development. The lack of cultural diffusion and its manifestation in cultural rigidity, however, diminished the ability of these societies to adapt to a new technological paradigm, which delayed their industrialization and, thereby, their take-off to a state of sustained economic growth. The theory contributes to the understanding of the advent of divergence and overtaking in the process of long-run development, attributing the dominance of some societies within a given technological regime to a superior operation of cultural assimilation, while the success of others in the switch between technological regimes to a higher frequency of cultural diffusion and the beneficial effect of diversity on the adaptability of society to a changing technological environment. Thus, in contrast to the cultural and institutional hypotheses, which posit a hierarchy of cultural and institutional attributes in terms of their conduciveness to innovation and their ability in fostering industrialization, the proposed theory suggests that the desirable degree of the relative prevalence of cultural assimilation versus cultural diffusion varies according to the stage of development. Enhanced cultural assimilation is optimal within a given stage of development, but is detrimental for the transition between technological regimes. Therefore, while cultural traits themselves do not necessarily have a differential effect on the process of development, it is the variation in the relative strengths of the forces of cultural assimilation and cultural diffusion, which together determine the heterogeneity of these traits, that is instrumental for comparative economic development.
\end{abstract}

Keywords: Cultural assimilation, Cultural diffusion, Cultural diversity, Geography, Economic development, Agriculture, Industrialization

JEL Classification Numbers: O11, O13, O14, O31, O33, O41, O43

\footnotetext{
${ }^{*}$ We thank Peter Howitt, Ross Levine, Louis Putterman, Yona Rubinstein, David Weil and seminar participants at Brown University for their helpful comments and suggestions. All remaining errors are ours.

${ }^{\dagger}$ Brown University, Quamrul_Ashraf@brown.edu

${ }^{\ddagger}$ Brown University, Hebrew Unniversity and CEPR, Oded_Galor@brown.edu
} 


\section{Introduction}

The contemporary distribution of income per capita across countries attests to a Great Divergence in their developmental paths since the Industrial Revolution, bearing witness to reversals in economic performance for some of the technological leaders in the pre-industrial era. The gap in per capita GDP between the richest regions of the world and the poorest increased from a modest 3 to 1 ratio in 1820 to an astounding 18 to 1 ratio in 2000 (Maddison, 2001). Moreover, historical evidence indicates that, as late as the end of the 1st millennium $\mathrm{CE}$, the civilizations of Asia were well ahead of Europe in both wealth and knowledge. ${ }^{1}$ Nonetheless, by the time of the Industrial Revolution in the 18th century, Europe had already overtaken these societies (Landes, 1998).

This research argues that variations in the interplay between the forces of cultural assimilation and cultural diffusion have played a significant role in giving rise to differential patterns of economic development across the globe, contributing to the Great Divergence and to reversals in economic performance. In particular, societies that were geographically less vulnerable to cultural diffusion benefited from enhanced assimilation, lower cultural diversity and, thus, greater accumulation of society-specific human capital, flourishing in the technological paradigm that characterized the agricultural stage of development. The lack of cultural diffusion and its manifestation in greater cultural rigidity, however, diminished the ability of these societies to adapt to a new technological paradigm, delaying the onset of their industrialization and, thereby, their take-off to a state of sustained economic growth.

The fundamental hypothesis of this research stems from the recognition that the evolution of the wealth of nations has been governed, in part, by the conflicting effects of cultural assimilation and cultural diffusion in different stages of development. The universal force of cultural assimilation (i.e., the homogenization of cultural traits within a society), contributed to the accumulation of society-specific human capital and, hence, to society's ability to efficiently exploit the existing technological frontier. However, vulnerability to cultural diffusion (i.e., the spread of cultural traits from one society to another) disrupted the force of assimilation in society, hampering the accumulation of society-specific human capital, while augmenting cultural diversity and, thus, the latent adaptability of society towards a looming technological regime. Societies that were historically characterized by geographical conditions conducive to cultural diffusion, therefore, incurred the costs associated with inefficiencies in socioeconomic organization within a given technological paradigm, operating inefficiently with respect to their technological frontier during the agricultural stage of development. Nonetheless, the more frequent disruption of the assimilation process in these societies conferred the long-run benefits of greater cultural fluidity and flexibility, stimulating their

\footnotetext{
${ }^{1}$ It has been argued by historians that Chinese technology long anticipated advancements during the Industrial Revolution in Europe. For example, in textiles, China had been employing water-driven machinery in the 12th century, five hundred years prior to the appearance of similar technologies in Europe, while the early use of coal and coke for iron smelting in China resulted in iron production amounts in the 11th century that were only matched in Europe seven hundred years later. Detailed historical accounts on the early dominance of Asian societies and the European overtaking have been given by Abu-Lughod (1989), Chaudhuri (1990), Goody (1996), Wong (1997), Frank (1998), Pomeranz (2000) and Hobson (2004).
} 
accumulation of universal human capital and fostering their ability to implement a paradigmatic shift of the technology frontier towards industry.

The proposed theory contributes to the understanding of the advent of divergence and overtaking in the process of long-run development, attributing the dominance of some societies within a given technological regime to a superior operation of cultural assimilation, while the success of others in the switch between technological regimes to a higher frequency of cultural diffusion and the beneficial effect of cultural diversity on the degree of adaptability of society to a changing technological environment.

The theory is based on three fundamental elements. The interaction between these elements generates a dynamic pattern that is consistent with the observed asymmetrical evolution of societies from an epoch of Malthusian stagnation to a regime of sustained economic growth, characterized by a Great Divergence in cross-country income per capita as well as reversals in the economic performance of some societies.

The first element pertains to the role of cultural assimilation in enhancing the intergenerational transmission, and, thus, the accumulation, of society-specific human capital. ${ }^{2}$ Cultural assimilation reduces diversity by standardizing sociocultural traits (e.g., norms, beliefs, ethics and codes of conduct) in society. It improves the efficiency with which society-specific human capital is transmitted across generations, thereby, augmenting total factor productivity with respect to the available production technologies. This observation is consistent with empirical evidence on the development-promoting effects of greater social cohesion or social capital. ${ }^{3}$

The second element embodies the notion that cultural diffusion, as reflected by the frequency of emergence of alternative modes of behavior in society, generates greater fluidity and flexibility that enhances the accumulation of knowledge, and, thus, more widely-applicable general human capital, expanding the economy's production possibility frontier and complementing its ability to advance and adapt to a new technological paradigm. This view is broadly consistent with theoretical and empirical evidence on the creativity-promoting effects of diversity in the workforce. ${ }^{4}$ Cultural

\footnotetext{
${ }^{2}$ This implicitly invokes an evolutionary theory, pioneered by Cavalli-Sforza and Feldman (1981) and Boyd and Richerson (1985), where the intergenerational transmission of cultural traits occurs both vertically (i.e. from parents to children) and horizontally (i.e. from role models in society to the younger generation). In the context of the proposed theory, a higher prevalence of conformism in the adult generation would imply smaller discrepancies between parental traits and those in society at large and, thereby, a more consistent transmission of conformist attitudes to the succeeding generation. For explicit applications of this evolutionary framework in the economics literature, see Bowles (1998), Bisin and Verdier (2000, 2001) and Spolaore and Wacziarg (2006).

${ }^{3}$ See, Knack and Keefer (1997), Temple and Johnson (1998), Zak and Knack (2001) and Gradstein and Justman (2002). The reader is also referred to Fukuyama (1995) for general arguments based on a historical perspective. In addition, Spolaore and Wacziarg's (2006) finding that the developmental gap between societies is negatively associated with the degree of their cultural or genetic similarity, arguably due to lower barriers to technology adoption, is related to the concept that cultural homogeneity within societies confers beneficial effects on their economic development in the proposed theory.

${ }^{4}$ Hong and Page (2001) provide a theoretical formalization of this idea, proving that a group of "cognitively diverse" problem solvers can find optimal solutions to difficult problems, and that a more diverse group of people with limited abilities can outperform a homogeneous group of high ability problem solvers. Moreover, Berliant and Fujita (2006) develop a microeconomic model of knowledge creation through cooperative interactions between people and demonstrate that heterogeneity is essential for successful cooperation in the joint creation of ideas. In the context
} 
diffusion, therefore, has an ambiguous effect on total factor productivity. Productivity is fostered on one hand by the accumulation of general human capital, and diminished on the other by inefficiencies in the intergenerational transmission of society-specific human capital.

The third element is designed to capture the importance of general human capital in promoting socioeconomic transitions to a new technological regime that is potentially more advanced in terms of per capita income. Consistent with historical evidence on the transition from agriculture to industry, the economy is characterized by a greater complementarity between the advancement of the knowledge frontier and technological inventions that are applicable to industrial production as opposed to agricultural production. ${ }^{5}$

Cultural traits (i.e., conformist and nonconformist attitudes towards the prevailing culture) are transmitted intergenerationally. In the absence of forces operating on these traits, individuals possess their parental cultural dispositions and the proportion of nonconformists in a society's working population thus remains constant over time. Individuals, however, are subjected to two cultural forces that generate opposing effects on the evolution of a society's cultural composition with respect to the prevalence of nonconformism: cultural assimilation and cultural diffusion. The former represents forces, internal to society, that lower the prevalence of nonconformism, via the homogenization of cultural traits. The latter, in contrast, represents geographically determined forces, external to society (e.g., the influence of a nearby foreign culture), that raise the prevalence of nonconformism, via the periodic introduction of heterogeneity in cultural traits.

In particular, the economy's population, being composed of both conformist and nonconformist individuals, is subject to the inherent gravitational inertia of cultural assimilation, which functions to homogenize the discordant attitudes in society and, thereby, reduce the degree of cultural heterogeneity in the population over time. The process of assimilation, however, is opposed by the geographically governed forces of cultural diffusion, whereby the periodic emergence of new behavioral attitudes and ideas in society, via cross-cultural contact, functions to increase the nonconformist fraction of the population over time.

In early stages of development, the economy is in a Malthusian regime where output is generated exclusively by an agricultural sector that is subject to decreasing returns to labor. Technological progress is rather gradual, occurring via relatively small increments to the economy's stock of knowledge, which is positively affected by the size of the population and the degree of its cultural heterogeneity. Resources generated by technological progress are channeled primarily towards an increase in population size, and the economy evolves along a dynamic path, character-

of team theory, Prat (2002) has established that heterogeneity raises team productivity when jobs within teams are complementary to one another. Similarly, Lazear (1999a, 1999b) has also discussed how diversity in a productive unit can raise overall productivity once the costs associated with language barriers are taken into account. The benefits of heterogeneity are further highlighted by Ottaviano and Peri (2005, 2006) who have empirically demonstrated the productivity enhancing effects of ethnic and cultural diversity in American cities.

${ }^{5}$ See, for example, Mokyr (2002) for a detailed historical account on the role of knowledge in bringing about and sustaining the Industrial Revolution. The broad definition of knowledge provided therein is consistent with the concept of general human capital in the current theory. The importance of general human capital in the adoption of modern modes of production is also stressed in the recent model of Lester (2006). 
ized by growing population and total factor productivity, towards a Malthusian equilibrium where income per capita remains stagnant.

The transition from agriculture to industry in the process of development is brought about by sustained growth in the latent productivity of manufacturing labor. The larger degree of complementarity between the expansion of the knowledge frontier and technological advancements applicable to industrial production sustains the endogenous growth of latent manufacturing productivity, which ultimately leads to the adoption of industry in later stages of development, paving the way for a take-off from the Malthusian epoch. Upon the adoption of industry, the economy emerges into a Post-Malthusian regime of development where output is generated using both the agricultural and a manufacturing production technology. The endogenous growth of total factor productivity in manufacturing, coupled with intersectoral labor mobility, sustains a dynamic path characterized by endogenously growing population and income per capita. ${ }^{6}$

The interaction between culture and the process of development is examined based on the significance of their coevolution for Malthusian equilibrium outcomes in the agricultural stage of development, and on the timing of the take-off from agriculture to industry. In the agricultural stage, an economy characterized by a relatively higher proportion of cultural nonconformists in its working population is also associated with a relatively inferior Malthusian steady-state, at least in terms of the level of productivity per worker and the size of its working population. This inferiority stems from the fact that the adverse effect of nonconformism on the transmission of society-specific human capital outweighs its beneficial role in the moderate advancement of rural productivity, via its contribution to cultural heterogeneity in the expansion of the knowledge frontier. The longrun level of income per capita in this stage of development, however, is unaffected by the higher prevalence of cultural nonconformism since the resulting lower level of productivity per worker is counter-balanced by a smaller size of the working population.

The prevalence of cultural nonconformism, however, also has an effect on the timing of industrialization and, thus, on the take-off to a state of sustained economic growth. The earlier take-off from the Malthusian steady-state by a society with a larger, but still moderate, proportion of cultural nonconformists stems from the fact that the beneficial effect of nonconformism on the advancement of knowledge, and, therefore, on the advancement of industrial productivity relative to that in agriculture, outweighs its eroding effect on the intergenerational transmission of societyspecific human capital. However, if the proportion of nonconformists is too large, an increase in their prevalence raises the flow of ideas while increasing the degree of anarchy in society, acutely disrupting the transmission of society-specific human capital. The rate at which new ideas are

\footnotetext{
${ }^{6}$ Since the goal of the theoretical analysis is to unravel the effects of the prevalence of nonconformism on the properties of the Malthusian equilibrium as well as the timing of the take-off from the Malthusian epoch, the model abstracts from the forces that ultimately lead to a demographic transition and the emergence of sustained economic growth. Incorporating human capital and a quality-quantity trade-off in parental fertility choices would generate a demographic transition, eventually leading to the emergence of a sustained growth regime, distinguished by rising income per capita and zero (or, perhaps, even negative) growth in population. This modification, however, would significantly complicate the analysis without altering the main insights.
} 
implemented and productivity is advanced in the economy is, therefore, diminished.

Variation in the moderate prevalence of nonconformism across societies is, thus, associated with the phenomenon of overtaking in global economic development. A higher prevalence of nonconformism generates an inferior outcome in the agricultural stage of development, but ultimately stimulates an earlier industrialization and, thus, an earlier take-off to a state of sustained economic growth. As such, the cultural composition of societies can have a profound effect on their historical experience with regard to the process of economic development.

The effect of initial geographical conditions on the evolution of the cultural composition of societies and, thus, on comparative development is examined based on their effects on Malthusian equilibrium outcomes in the agricultural stage of development, and on the timing of industrialization and the take-off to a state of sustained economic growth. An economy that is characterized by greater geographical vulnerability to foreign cultural influences, and, hence, by more cultural diffusion, is also associated with a relatively higher proportion of cultural nonconformists in its population and, thereby, a relatively inferior Malthusian steady-state, in terms of the level of productivity per worker and the size of its working population. This inferiority stems from the fact that greater geographical vulnerability to cultural diffusion, leading to a higher prevalence of nonconformism, has an adverse effect on the transmission of society-specific human capital that outweighs its productive role in the moderate advancement of rural productivity, via its contribution to cultural heterogeneity in the expansion of the knowledge frontier.

As long as the prevalence of nonconformism is not sufficiently high so as to induce excessive dissonance in the organization of society, however, an increase in cultural diffusion, due to more vulnerable geographical conditions, expedites the onset of industrialization and, thus, the take-off to a state of sustained economic growth. The earlier take-off from the Malthusian steady-state by a society that possesses a higher, but still moderate, geographical vulnerability to cultural diffusion, and, therefore, has a higher prevalence of moderated nonconformism, stems from the fact that the beneficial effect of nonconformism on the advancement of knowledge, and, hence, on the advancement of industrial productivity relative to that in agriculture, outweighs its eroding effect on the intergenerational transmission of society-specific human capital. In contrast, if the degree of geographical vulnerability to cultural diffusion is too large, and, thus, the prevalence of nonconformism too high, an increase in vulnerability raises the degree of anarchy in society, which severely disrupts the transmission of society-specific human capital. Thus, while a higher degree of vulnerability to cultural diffusion increases the flow of new ideas, the rate at which these ideas are implemented and productivity is advanced in the economy is diminished.

Variation across societies over a moderate range in the degree of geographical vulnerability to cultural diffusion is, thus, associated with the phenomenon of overtaking in global economic development. Specifically, a higher degree of geographical vulnerability generates an inferior economic outcome in the agricultural stage of development, but ultimately stimulates an earlier industrialization and, thus, an earlier take-off to a state of sustained economic growth. By influencing the 
cultural composition of societies throughout history, geography confers a profound effect on their experience with regard to the process of economic development.

\section{Advances with Respect to the Related Literature}

The origin of the Great Divergence has been a source of controversy. The relative influence of geographical, cultural and institutional factors, human capital formation, ethnic, linguistic, and religious fractionalization, colonialism and globalization has been at the center of the debate regarding the origins of the remarkable transformation of the world income distribution over the past two centuries.

The significance of sociocultural factors in giving rise to the differential development trajectories of Europe and Asia has been the focus of an influential hypothesis raised originally by Max Weber, in his works on the sociology of religion $(1905,1922)$, and promoted more recently by Hall (1986), Lal (1998), Landes $(1998,2006)$ and others. ${ }^{7}$ The central premise of the cultural hypothesis is implicitly that societal norms, customs and ethics can be ranked in terms of their ability to nurture technological innovation and the "entrepreneurial spirit" of capitalist development. The Weberian viewpoint, therefore, places the proclivity of European culture towards rationalism and the objective "disenchantment of the world" at the forefront in explaining the rise of industry in the Western world. ${ }^{8}$ Moreover, the emphasis placed by Oriental culture on rigid aesthetic values of self-perfection and filial piety is held responsible for the delayed transition to a sustained growth regime in the East.

The theory advanced in this study differs significantly from the existing sociocultural hypothesis that underlines the existence of a hierarchy of cultural attributes according to their conduciveness to innovation and their applicability towards an industrial take-off. While society-specific cultural traits (e.g., norms, beliefs and ethics) may well have some differential effects on the process of development, the proposed hypothesis suggests that it is the variation in the relative strengths of the forces of cultural assimilation and diffusion, which operate over these traits, that is instrumental for comparative economic development. ${ }^{9}$ The universal force of cultural assimilation, working to

\footnotetext{
${ }^{7}$ The term "culture" in this regard refers to the set of society's norms, beliefs, customs, traditions, taboos, codes of conduct, etc., and is, therefore, distinct from the notion of "institutions", which has traditionally been regarded in the literature as embodying the sociopolitical environment as determined by constitutions, rule of law and property rights. North $(1981,1991)$, however, has advanced a broader notion of "institutions" in terms of a set of constraints imposed to structure human socioeconomic interaction. These include both "informal constraints" such as customs and traditions as well as "formal constraints" such as laws and property rights.

${ }^{8}$ Some economists have interpreted the emergence of the Weberian "capitalist spirit" in terms of the endogenous evolution of preferences. Doepke and Zilibotti (2005a, 2005b), for example, stress the role of the subjective discount factor in a theory of occupational choice and attribute the rise of capitalism to a complementarity between human capital intensive occupations and "patience". In addition, Galor and Michalopoulos (2006) have provided an evolutionary growth theory emphasizing the evolution of risk aversion and it's interaction with the process of development.

${ }^{9}$ While not the focus of the current study, the endogenous emergence of social norms has been motivated from the perspective of contract enforceability by Kandori (1992), Greif $(1993,1994)$ and others. Furthermore, in an approach complementary to the proposed theory, Heiner (1983) and Harrington $(1998,1999)$ have argued that the emergence
} 
acculturate the divergent attitudes in society towards it's customs and traditions, whatever these may be, leads to greater cohesion and social order over time, which enables society to function closer to the production possibility frontier of the existing technological paradigm. However, vulnerability to cultural diffusion, which diminishes the standardization of society-specific cultural traits over time, simulates the adaptability of society to a new technological paradigm and, thereby, expedites the onset of industrialization.

The role of favorable geographical conditions in fostering the earlier European take-off from Malthusian stagnation has been given precedence by Jones (1981), Diamond (1997), Pomeranz (2000) and others. ${ }^{10}$ They argue that the earlier rise of Europe could be attributed to its favorable natural resource base, abundant rainfall, temperate climate, lower disease-burden, and its geographical proximity to the New World, which facilitated the escape from the Malthusian trap via the alleviation of land constraints. The geographical hypothesis has also stressed an indirect role of geography in promoting the earlier European take-off. It has been argued, particularly by Jones (1981), that the natural barriers created by Europe's mountain chains and rivers prevented a single state from dominating the entire territory, and eventually led to sociopolitical fragmentation and competition, encouraging innovative activities that contributed to an earlier take-off.

The element of geographical determinism in the proposed theory is distinct from that raised in the literature regarding the direct effects of natural resource endowments (i.e. the influence of climate, rainfall, disease burden, etc.). Specifically, the proposed theory attributes differences in the frequency with which the force of cultural assimilation is hampered to variation in geographical characteristics that determine the likelihood of emergence of new attitudes and ideas within societies via cultural diffusion. Moreover, in contrast to the hypothesis of Jones (1981), where natural barriers within Europe served to delineate societies that competed with each other in a process that stimulated innovation and development for the region as a whole, the hypothesis in this paper is that such internal barriers prevented the cultural homogenization of the entire European continent and permitted a constant flow of cultural diffusion within the region, thereby, expediting the European transition to industry. ${ }^{11}$

The influence of institutions has been emphasized by North and Thomas (1973), North (1981), Landes (1998), and Mokyr (1990, 2002), amongst others, who argue that institutional factors that facilitated the protection of individual property rights and enhanced technological innovations and the diffusion of knowledge were the prime forces behind the earlier European transition to

of rigidity versus flexibility in social norms is governed by a social selection mechanism that rewards these attitudes differentially depending upon the degree of uncertainty in the socioeconomic environment. It should also be noted that norms themselves have been shown to affect economic outcomes, as demonstrated empirically by Barro and McCleary (2003), Guiso, Sapienza, and Zingales (2003, 2006) and Tabellini (2005).

${ }^{10}$ See, for example, Gallup, Sachs, and Mellinger (1999) and Olsson and Hibbs (2005).

${ }^{11}$ In addition, Simonton (2004) has convincingly argued for the differentiation of the interrelated but distinct concepts of political fragmentation and cultural heterogeneity. For instance, as surveyed by the author, while some empirical studies indicate a positive association between political fragmentation and innovation, others have found a negative correlation between these variables. Indeed, these contradictory findings have led to a reformulation of the Jones (1981) hypothesis in that "it is cultural heterogeneity that provides the crucial factor [for innovation], political fragmentation only proving relevant insofar as it is associated with such heterogeneity" (Simonton, 2004, p. 50). 
sustained economic growth. Moreover, the endogenous nature of sociopolitical institutions, coupled with the inherent exogeneity of geography, has recently prompted some researchers to propose that initial geographical conditions gave rise to persistent differences in institutional quality across regions. ${ }^{12}$ Engerman and Sokoloff (2000), for example, argue that societies initially characterized by geographical factors conducive to income inequality also implemented oppressive institutions designed to preserve the unequal distribution of wealth within their populations. Others, notably Acemoglu, Johnson, and Robinson (2002), have argued that historical reversals in the economic performance of societies have a colonial legacy that reflects the imposition of extractive institutions by European colonizers in regions that were relatively affluent in the pre-industrial era. ${ }^{13}$ The role of colonialism in giving rise to the phenomenon of overtaking through institutional inversions is clearly inapplicable, however, in explaining the delayed emergence of a sustained growth regime in China, which, as economic historians have argued, represents one of the most significant historical reversals in global economic development. ${ }^{14}$

In contrast to the institutional viewpoint, where the quality of sociopolitical institutions has an unequivocal effect on economic growth, the effect of the degree of cultural homogeneity in the proposed theory is ambiguous, with greater homogeneity improving the efficiency of intergenerational transmission of society-specific human capital on one hand, but also hampering the accumulation of universal human capital on the other. The force of assimilation, therefore, permits society's advancement within a given technological regime through a well-defined socioeconomic structure, but also comes at the opportunity cost of hindering its progress towards a potentially more advanced regime. ${ }^{15}$

The role of ethnic, linguistic, and religious fractionalization in the emergence of divergence through "growth tragedies" has been linked to their effect on the quality of institutions. Easterly and Levine (1997) and Alesina et al. (2003) have demonstrated that geopolitical factors that

\footnotetext{
${ }^{12}$ Recent empirical investigations by Acemoglu, Johnson, and Robinson (2001, 2002), Easterly and Levine (2003) and Rodrik, Subramanian, and Trebbi (2004), appear to support the hypothesis that the geographical determinism of contemporary economic development operates primarily through the effects of initial geographical conditions on institutional quality.

${ }^{13}$ Additional aspects of the long-run effects of European colonialism on comparative economic development are examined at a within-country level for India by Banerjee and Iyer (2005) and at a cross-country level for Africa by Bertocchi and Canova (2002). In general, the findings in these studies are broadly consistent with the notion of a deleterious institutional legacy of European colonialism in the colonized regions.

${ }^{14}$ An alternative hypothesis explaining how favorable geographical conditions could have given rise to historical reversals in economic performance has been advanced by Galor, Moav, and Vollrath (2006) who emphasize the negative impact of inequality in the distribution of land ownership on the emergence of human capital promoting policies such as public schooling and child labor regulations.

${ }^{15}$ The institutional viewpoint typically underscores more politically-governed aspects of social structure such as property rights, laws and constitutions, while this paper emphasizes the role of social cohesion that emerges naturally from the homogenization of cultural dispositions in society with respect to it's customs, traditions and codes of conduct. Using the terminology adopted in North's (1981) definition of institutions, the distinction here is that between society's formal and informal constraints. In particular, the proposed theory stresses the implementation of informal constraints in society, as governed by the extent to which the force of assimilation can operate without any external impediments. As such, the inertia of assimilation can also be interpreted as a "meta-constraint" where its quality captures society's ability to successfully indoctrinate subsequent generations to abide and follow the wellestablished societal norms, beliefs and ethics.
} 
brought about a high degree of fractionalization in some regions of the world, led to the implementation of institutions detrimental for economic growth and, consequently, to a divergence in developmental paths across societies. ${ }^{16}$ In contrast, one could view the current analysis as suggesting that heterogeneity in cultural dispositions (i.e., conformist and nonconformist attitudes) within a given ethnic group is conducive for industrialization, although the similar benefits from heterogeneity that is generated by the presence multiple ethnic groups is outweighed by the costs associated with interethnic conflicts.

Finally, the role of human capital formation and the onset of the demographic transition in giving rise to and sustaining the Great Divergence is stressed in the unified growth theories of Galor and Weil (2000), Fernández-Villaverde (2001), Galor and Moav (2002), Lucas (2002), Lagerlöf (2003, 2006), Doepke (2004), Galor and Mountford (2004, 2006), Galor (2005), Voigtländer and Voth (2006) as well as in recent work by Galor, Moav, and Vollrath (2006), and is demonstrated empirically by Glaeser et al. (2004). While tangential to the current analysis, these studies establish theoretically and quantitatively that the rise in the technologically driven demand for human capital in the second phase of industrialization, and its effect on human capital formation and on the onset of the demographic transition, were the central forces in the transition from stagnation to sustained economic growth and in the emergence of the associated phenomenon of the Great Divergence. In particular, they suggest that once the technologically driven demand for human capital emerged in the second phase of industrialization, the prevalence of human capital promoting institutions determined the extensiveness of human capital formation and, hence, the rapidity of technological progress, the timing of the demographic transition, the pace of the transition from stagnation to growth, and, thus, the contemporary distribution of income in the world economy.

\section{Historical Evidence}

Historical evidence suggests that, consistent with the proposed theory, the geographically governed intensities of cultural assimilation and diffusion were indeed a significant determinant of comparative economic performance during the Malthusian epoch and in the transition from agriculture to industry. Section 3.1, in particular, presents evidence that geographical isolation enhanced cultural homogeneity and stability, which permitted a relatively unimpeded accumulation of society-specific human capital and conferred Malthusian returns in terms of population density during the agricultural stage of development. Section 3.2, on the other hand, provides evidence demonstrating the long-run benefits of cultural diffusion in the promotion of innovation and, thereby, in fostering the transition from agriculture to industry.

\footnotetext{
${ }^{16}$ See also the recent study by Montalvo and Reynal-Querol (2005). These findings, however, have commonly been misinterpreted as implying that diversity is harmful for growth, which is not necessarily the case, as established by Lian and Oneal (1997). Moreover, based on the notion that some sociopolitical institutions are more conducive to harmony than others, Collier $(2000,2001)$ has argued that ethnic fragmentation should be less disruptive in more pluralistic societies. The studies of Collier and Gunning (1999), Easterly (2001) and Alesina and La Ferrara (2005) have indeed provided some empirical validation along these lines.
} 


\subsection{Isolation, Assimilation and Malthusian Prosperity}

The historical record on the experience of Chinese civilization throughout the agricultural stage of development is broadly consistent with the hypothesis of this research regarding the links between relative isolation from cross-cultural contact, cultural stability and Malthusian prosperity. It has long been argued by historians (e.g., Cressey, 1934; Elvin, 1973) that the remarkable stability and unity of Chinese civilization, that has remained culturally homogenous for some four thousand years, was due, in large part, to it's geographic isolation from the civilizations of India and the Western world in ancient times. China's location in the extreme eastern quarter of the Eurasian landmass as well as it's natural barriers such as the Himalayas, the Tian Shan and Altay mountain ranges, the Taklamakan and Gobi deserts, and the Pacific Ocean ensured that, throughout most of it's early history, China had relatively infrequent exposure to cultural influence from other advanced civilizations. Indeed, the origin of the sinocentric notion of China as the "Middle Kingdom", or the center of human civilization, is often attributed to it's early isolation from cross-cultural contact (Cressey, 1934). The lower geographical vulnerability to cultural diffusion therefore permitted an unimpeded accumulation of society-specific human capital in China as manifested in the Confucian traditions of filial piety and reverence for highly-codified social hierarchies. The intergenerational transmission of society-specific human capital was further enhanced in China by such institutions as the world's oldest civil service examination system, and by technological inventions such as papermaking and printing, all of which were instrumental for the preservation and efficient dissemination of Confucian ideology.

Despite the natural insulation offered by China's geographical barriers, historical evidence demonstrates some major instances of external cultural infiltration in China as exemplified by the introduction of Buddhism from India during the Han dynasty (206BCE-220CE), and by the Mongol and Manchu invasions in the 13th and 17th centuries. Nevertheless, in each of these instances the force of assimilation assured relatively minimal disruptions to the long-standing sociocultural traditions of Chinese civilization. For example, by the time Buddhism gained prominence as one of the major state religions in China during the Tang dynasty (618CE-907CE), it had already been infused with existing Chinese philosophies, particularly Taoism, and was being disseminated in a distinctly sinicized form known as Ch'an (Zen) Buddhism. Subsequently, during the Song dynasty (960CE-1279CE), elements of Buddhism, Confucianism and Taoism were successfully synthesized to produce the reconstituted philosophy of Neo-Confucianism, which remained the orthodox state doctrine until the end of the Chinese imperial system (Ch'en, 1964). Moreover, the historical record on the Yuan (Mongol) dynasty (1279CE-1368CE) as well as the Qing (Manchu) dynasty (1644CE1912CE) indicates that the nomadic steppe invaders of China, especially the Manchus, were largely

absorbed into the existing sociocultural fabric of Chinese civilization, with the conquerors ruling almost entirely in the well-established Confucian tradition (Ho, 1967).

Historical evidence coming from some of the most prosperous dynastic periods of Chinese civilization, encompassing the Han, Tang and Song dynasties, is consistent with the link between 
the intense accumulation of society-specific human capital and higher Malthusian returns in the proposed theory. While agrarian technological progress, such as the introduction of iron ploughing techniques during the Han period or the state promotion of early-ripening rice strains by the Song, undoubtedly contributed to the greater Malthusian prosperity of these periods (Needham and Bray, 1984; Elvin, 1973), the evidence is also suggestive of higher demographic returns to enhanced society-specific human capital. In particular, the society-specific human capital promoting institution of the civil service examination system was established by the Han dynasty and refined during the Tang and Song periods (Fairbank, 1992). Further, technologies like paper-making and printing that significantly enhanced the dissemination and perpetuation of Confucian philosophies were also invented and improved upon in these eras (Needham and Tsuen-Hsuin, 1985). Interestingly, as depicted in Figure 1, the Han, Tang and Song dynastic eras are also associated with periods of progressive growth in the population density of China. The Song dynasty, in particular, witnessed an unprecedented demographic explosion occurring between the 11th and 12th centuries when the population of China surpassed 100 million (McEvedy and Jones, 1978).

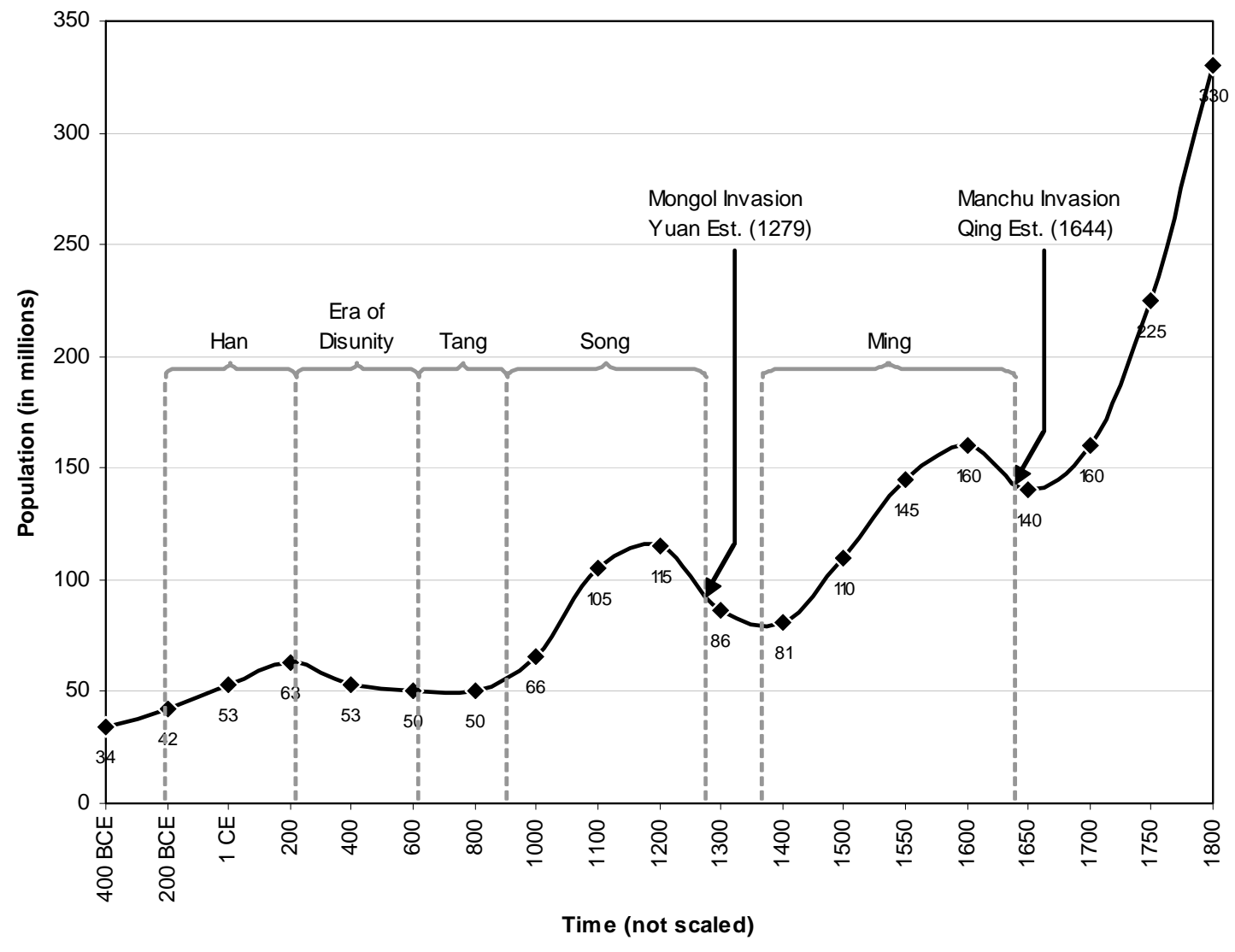

Figure 1: The Time Path of Population in Dynastic China, 400BCE-1800CE (Source: McEvedy and Jones, 1978) 
While the homogenizing force of assimilation ultimately ensured the successful sinicization of external influences throughout China's history, the evidence on population recession during episodes of foreign cultural influx accords well with the proposed hypothesis in terms of the disruptive effects of heterogeneity on Malthusian returns. For example, the collapse of the powerful Han dynasty ushered in nearly four centuries of cultural instability and fragmentation. The period was marred by civil wars during the Three Kingdoms era (220CE-280CE), and by relatively minor but frequent nomadic invasions, forcing the southward migration of the Jin dynasty (265CE-420CE), which eventually led to further social disunity during the turbulent period of the Northern and Southern dynasties (420CE-589CE) (see, e.g., Gernet, 1982). In line with the theory of this research, the unstable environment of this era, that also experienced an increase in religious heterogeneity with the rise of Buddhist thought and practices at the expense of Confucian ideology, saw about a $20 \%$ decline in China's population. ${ }^{17}$

Further evidence on the detrimental effects of cultural heterogeneity, that introduces higher inefficiencies in the intergenerational transmission of society-specific human capital according to the proposed hypothesis, is provided by the demographic trends in the aftermath of the Mongol and Manchu invasions of imperial China. As depicted in Figure 1, while the recovery of the population occurred over the course of only 50 years following the Manchu invasion, it took about three times longer for the population to regain the level that existed prior to the Mongol invasion. ${ }^{18}$ Although this discrepancy is due, in part, to the greater devastation inflicted by the Mongols, the difference in the extent to which these groups were assimilated into the sociocultural traditions of Chinese civilization is also regarded as a contributing factor. Indeed, the relatively lower instability resulting from the establishment of the Qing dynasty has been attributed to the fact that, as vassals of the preceding Ming dynasty (1368CE-1644CE), the Manchus, unlike their Mongol counterparts four centuries earlier, were already highly sinicized by the time of conquest (Ho, 1967).

Following the disruptions associated with the Mongol invasion, China embarked on a trajectory of rapid demographic expansion that lasted well into the modern era. The population doubled from about 80 million to 160 million in the Ming era and tripled under the Qing dynasty, reaching over 430 million by the mid-19th century (McEvedy and Jones, 1978). This monumental growth is

\footnotetext{
${ }^{17}$ It is interesting to note that processes leading to greater cultural heterogeneity were also associated with declining population density over this period in Europe. Following the height of prosperity under the Roman Empire, which represented 36 million European subjects at around 200CE, the population declined to 26 million by $600 \mathrm{CE}$ and only climbed to about 29 million by $800 \mathrm{CE}$, representing an overall decline of $19 \%$ across six centuries (McEvedy and Jones, 1978). While climatic downturns have been held partially responsible for this decline, the fact that this period also witnessed increased cultural instability and heterogeneity resulting from the "Barbarian Invasions" is supportive of the hypothesis set forth in this paper. To elaborate, the first phase of this migration period (300CE-500CE) saw the movement of various Germanic peoples into areas of the former Roman empire (e.g. the Ostrogoths in Italy, the Franks and Visigoths in France and Spain, and the Angles and Saxons in Britain) while the second phase (500CE$700 \mathrm{CE}$ ) comprised the migration of Slavic tribes, particularly the Bulgars, into Eastern Europe in the 7th century as well as the invasion of the Iberian peninsula by the Arabs in the 8th century (McNeill, 1963).

${ }^{18}$ The depiction of smooth demographic downturns during episodes of invasion in Figure 1 is, of course, entirely a by-product of the unavailability of sufficient data points. It is more likely that these nomadic invasions inflicted negative demographic "shocks" with the population expansion regimes of the preceding periods lasting just until the onset of the conquests.
} 
partly attributable to an increase in food supply resulting from the introduction of "New World" crops, such as maize and sweet potatoes, and the spread of innovative Song period cultivation methods like multiple-cropping that led to substantially higher yields (Deng, 1993). Beyond agrarian technological progress, the relatively high degree of cultural and institutional stability of the Ming and Qing periods are also considered to be significant factors contributing to the population expansion during this era. Consistent with the hypothesis of this research regarding the Malthusian returns to enhanced society-specific human capital, Confucian ideology was more widespread in this period of China's history than ever before (Chow, 1994; Elman, 2000). The state-imposed isolation throughout most of the Ming-Qing era further ensured that traditional Chinese culture was almost impervious to external influence during this period. More schools in both rural and urban areas were established as the cost of education fell with technological improvements in printing while the number of academies preparing candidates for the civil service examination multiplied. The publishing of Neo-Confucian texts flourished and the period saw a general increase in ideological literacy, thereby, strengthening the unique cultural uniformity of Chinese civilization that remained largely unchanged through the beginning of the modern era.

\subsection{Diffusion, Innovation and the Transition to Industry}

The proposed theory suggests that a society's exposure to cultural diffusion, which leads to greater cultural heterogeneity through the introduction of external cultural influences, played a significant role in the promotion of innovation and technological creativity throughout it's history. In line with this hypothesis, both creativity researchers and historians have long stressed the important link between cultural diversity and creative florescence. It has been suggested, for example, that the "exposure to different and even contrasting cultural stimuli" is indeed a fundamental "creativogenic factor" (Arieti, 1976, p. 320) and that "a [cultural] milieu [of different ideas, beliefs and patterns] contains richer material for a new synthesis or creative combinations than a cultural milieu of monotonous stereotypes" (Sorokin, 1947, p. 542). Moreover, the historical record of world civilization demonstrates that many societies had experienced a surge in creativity after having been exposed to foreign ideas and peoples (see, e.g., Toynbee, 1957; McNeill, 1963). The Golden Age of Hellenistic civilization in Greece, for instance, is thought to have occurred as a result of the diffusion of diverse ideas from the civilizations of Egypt, Persia and Mesopotamia that culminated to a new creative synthesis. In addition, the European Renaissance of the 12th century, that ultimately paved the way to the Scientific Revolution of the 17th century, is historically attributed to the diffusion of scientific thought and philosophies resulting directly from cross-cultural contact between Europe and the Islamic world (Sarton, 1927; Sarton, 1931).

Beyond the history of Western civilization and consistent with the generality of the proposed hypothesis, evidence on the link between cultural diffusion and innovation is present in the historical record of Asian civilizations as well. In particular, the spread of Buddhism to China from India initiated a period of intellectually productive exchange between the two civilizations that lasted 
several centuries (see, e.g., Ch'en, 1964; Gernet, 1982). The returns arising from this diffusion are best exemplified by scientific progress in China, particularly in the fields of astronomy and mathematics, during the Tang dynasty. Chinese scholars of this period, most of them Buddhist monks who were familiar with Sanskrit, are known to have translated the Indian literature on mathematics and, in the process, introduced the Hindu decimal system in China. ${ }^{19}$

Further evidence on the innovation promoting effects of cultural diffusion comes from a sociometric study by Simonton (1997) that applied generational time-series analysis to detect whether cultural cross-fertilization and the influx of alien ideas had a positive influence on national achievement in Japan over the period spanning CE 580-1940. Using a sample of 1803 eminent Japanese figures grouped into 20-year generations, together with time-series data on various measures of openness to extracultural influence (such as the number of foreign immigrants who left a mark on Japanese history and the number of eminent Japanese who travelled abroad or studied under foreigners), the research found some significant cross-lagged correlations between creative achievement and cultural openness to the non-Japanese world. ${ }^{20}$

Historical evidence coming from the Golden Age of Islamic civilization is also consistent with the hypothesis of this research regarding the association of innovative activity with cultural heterogeneity. At the height of Islam under the Abbasid Caliphate (750CE-1258CE), the city of Baghdad was one of the largest and most cosmopolitan in the world, representing a highly diverse population composed of Muslims, Jews, Christians and polytheistic adherents from various parts of a vast empire encompassing North Africa, the Middle East and Central Asia. Moreover, in line with the proposition that "the point of junction of various cultural streams supplies a larger number of the elements necessary for a new creation" (Sorokin, 1947, p. 542), Baghdad was also the center of international scholarly achievement in the High Middle Ages (Nasr, 1968). Building on the scientific traditions of the Greek and Hindu civilizations, eminent figures from diverse religious and ethnic backgrounds, such as the Persians Al-Khwarizmi and Ibn Sina (Avicenna), the Nestorian Hunayn ibn Ishaq and the Sabean Thabit ibn Qurra (Thebit) to name a few, made several significant contributions in the fields of mathematics, astronomy, medicine and chemistry (Sarton, 1927). As noted by historians in recognition of the returns from cultural heterogeneity, "the fusion of Indian and perhaps Babylonian with Hellenistic ideas stimulated fresh discoveries and the development of some important scientific devices [in this period]" (McNeill, 1963, p. 438). Nonetheless, while these accomplishments were being further expanded and improved upon in Europe during the 12 th and 13th centuries, Islamic civilization ultimately declined into intellectual stagnation by the beginning of the early modern era. Consistent with the arguments of the proposed theory, creativity

\footnotetext{
${ }^{19}$ One of the many intellectual products of this cultural diffusion regime was the Buddhist monk Yi Xing, identified as "the greatest Chinese mathematician and astronomer of his time" (Needham, 1956, p. 427), who made significant contributions in combinatorics and employed Indian trigonometry for advances in calendrical calculations.

${ }^{20}$ For instance, the number of eminent Japanese figures in medicine in generation $t$ was found to have a significant correlation of 0.27 with foreign travel in generation $t-2$ while achievements in the spheres of business and religion were contemporaneously correlated with a composite measure of outside influence, possessing significant correlation coefficients of 0.25 and 0.5 respectively (Simonton, 1997).
} 
researchers and historians (e.g., Simonton, 1997; Landes, 1998) have attributed this descent in innovative activity to an increase in cultural homogeneity resulting from a deliberate resistance to the influx of new ideas from the non-Islamic world.

Finally, the examples of migrant minority groups, particularly within Europe in the 16th and 17th centuries, that conferred substantial economic gains to their host societies provide additional documented evidence in support of the proposed hypothesis. ${ }^{21}$ Historical studies on the significant economic effects of the Protestant migrations in Europe during this period suggest that these migrant groups "frequently transplanted new ideologies and attitudes towards economic activity as well as widely diversified technical knowledge" (Scoville, 1951, p. 350). Some of these influential migratory waves include the movement of Flemish, Walloon and Dutch Protestants from the Low Countries to England, Holland and Switzerland in the late 16th century, and the migration of the French Huguenots to England, Ireland, Prussia and elsewhere as a result of events following the revocation of the Edict of Nantes by Louis XIV in 1685. Indeed, historical records demonstrate that the Protestant migrations of the late 16th century were associated with notable improvements in several industries, including textiles, glass-making and printing, as well as the introduction of new agricultural practices in the host countries. Commenting on the extraordinary impact of the Dutch Protestant migrations, Scoville (1951, p. 355) has argued that "it could not have been entirely fortuitous that England and Holland in particular, and to a lesser extent Switzerland, experienced a marked acceleration in their economic and industrial growth at about the same time that the refugees were arriving." Evidence of similar effects resulting from the French Huguenot migrations comes, for example, from Ireland where substantial developments in textile manufacturing resulted in a 16-fold increase in the country's linen exports between 1700 and 1750 (Scoville, 1951).

\section{The Basic Structure of the Model}

Consider a perfectly competitive overlapping-generations economy in the process of development where economic activity extends over infinite discrete time.

\subsection{Cultural Assimilation and Cultural Diffusion}

Individuals are characterized by a cultural trait that determines their attitude towards the prevailing cultural norms in the economy. They can be either conformist or nonconformist with respect to

\footnotetext{
${ }^{21}$ Another documented example of the beneficial role of minorities comes from the history of the Jewish community in Islamic Spain under the Caliphate of Córdoba in the 10th and 11th centuries. During this period, typically referred to as the Golden Age of Al Andalus, the Sephardic Jewry contributed significantly to the economic and commercial fabric of Islamic Spain, specializing in a diverse set of skilled occupations and playing a dominant role in both local and foreign trade (Ashtor, 1973; Botticini and Eckstein, 2006). In addition, members of the Jewish community also held important state offices, as exemplified by Hasdai ibn Shaprut who was an appointed court physician and counselor to the Caliph Abd ar-Rahman III. Interestingly, consistent with the link between cultural heterogeneity and creative activity in the proposed hypothesis, this period also witnessed a surge in diverse intellectual accomplishments, typified by the works of such influential scholars as the Muslim physician Ibn Rushd (Averroes) and the Jewish philosopher Moshe ben Maimon (Maimonides).
} 
the prevailing culture. Cultural traits are transmitted intergenerationally. In the absence of forces operating on these traits, individuals possess their parental cultural dispositions and the fraction of nonconformists in society remains constant over time. However, individuals are subjected to two cultural forces that generate opposing effects on the fraction of nonconformists in the adult population: cultural assimilation and cultural diffusion. Cultural assimilation represents cultural changes due to internal forces that operate towards the homogenization of traits and, thus, reduces the fraction of nonconformists in society. Cultural diffusion, in contrast, represents cultural changes due to external forces (e.g., the influence of a nearby foreign culture) that increases the heterogeneity of traits and, thus, raises the fraction of nonconformists in society. ${ }^{22}$

Due to the forces of cultural assimilation, individuals born to nonconformist parents deviate with probability $\sigma \in(0,1)$ from their parental trait and become conformists. Hence, a proportion $\sigma$ of the fraction of nonconformists, $\omega$, adopt a conformist disposition in the next period, with the remaining proportion, $(1-\sigma)$, maintaining nonconformism. On the other hand, due to the forces of cultural diffusion, which reflect the geographically determined vulnerability of the domestic culture to foreign cultural influences, individuals who are born to conformist parents, deviate with probability $\mu \in(0,1)$ from their parental disposition to adopt the nonconformist trait present in the environment. ${ }^{23}$ Consequently, a proportion $\mu$ of the fraction of conformists, $(1-\omega)$, become nonconformists in the next period.

The steady-state fraction of nonconformists is therefore $\omega=(1-\sigma) \omega+\mu(1-\omega)$, which implies that

$$
\omega=\mu /(\sigma+\mu) \equiv \omega(\mu, \sigma)
$$

where $\partial \omega / \partial \mu>0$ and $\partial \omega / \partial \sigma<0$. Namely, $\omega$ is increasing in the degree of geographical vulnerability to cultural diffusion, $\mu$, and decreasing in the intensity of cultural assimilation, $\sigma$.

\subsection{Production}

In every period, the economy produces a single homogenous good in a rural (agricultural) sector and, possibly, in a manufacturing (industrial) sector, employing labor and land in the production process. Labor is supplied inelastically by households and evolves over time at the endogenously determined rate of population growth. The supply of land, however, is exogenously determined and remains constant over time. ${ }^{24}$ In early stages of development, the manufacturing sector is not

\footnotetext{
${ }^{22}$ Alternatively, the diffusion process can be equivalently considered in terms of members of a foreign population replacing a fraction of the domestic population, where the foreigners are, by definition, nonconformists vis-a-vis the domestic sociocultural norms. In the context of the Malthusian regime, this could occur as a result of foreign invasions of the domestic population.

${ }^{23}$ It is plausibly assumed that individuals in the Malthusian regime did not envision the eventual occurrence of the Industrial Revolution and the importance of diversity for an earlier transition to industry. Hence, the evolution of cultural traits as described do not reflect a strategic choice by individuals, but rather the operation of the inevitable forces of cultural assimilation and cultural diffusion.

${ }^{24}$ The presence of a fixed factor implies that there are diminishing returns to labor in the rural sector, an essential ingredient for the emergence of a stable Malthusian equilibrium in early stages of development.
} 
economically viable and production is conducted exclusively in the rural sector. However, due to its relatively faster rate of growth in productivity, the manufacturing sector ultimately becomes economically viable and both sectors are jointly operated in later stages of development.

\subsubsection{Production in the Rural and Manufacturing Sectors}

The output produced in the rural sector in period $t, Y_{t}^{R}$, is governed by a Cobb-Douglas, constantreturns-to-scale production technology such that

$$
Y_{t}^{R}=\left(A_{t}^{R} X\right)^{1-\alpha}\left(L_{t}^{R}\right)^{\alpha} ; \quad \alpha \in(0,1),
$$

where $L_{t}^{R}$ is the amount of labor employed in the rural sector in period $t, X$ is the amount of land, and $A_{t}^{R}$ is the level of rural productivity in period $t$. For simplicity the amount of land is normalized such that $X=1$.

The output of the manufacturing sector in period $t, Y_{t}^{M}$, is determined by a linear, constantreturns-to-scale production technology such that

$$
Y_{t}^{M}=A_{t}^{M} L_{t}^{M}
$$

where $L_{t}^{M}$ is the amount of labor employed in the manufacturing sector in period $t$, and $A_{t}^{M}$ is the level of manufacturing productivity in period $t$.

The total labor force in period $t, L_{t}$, is allocated between the two sectors and, therefore,

$$
L_{t}^{R}+L_{t}^{M}=L_{t}
$$

where $L_{t}>0$ in every period $t$.

As will become apparent, in early stages of development, when the productivity of manufacturing labor, $A_{t}^{M}$, is low relative to that of rural labor, output is produced using only the rural technology. However, in later stages of development, when $A_{t}^{M}$ rises sufficiently relative to the productivity of rural labor, the manufacturing technology becomes economically viable.

\subsubsection{Factor Prices and Aggregate Labor Allocation}

Producers operate in perfectly competitive markets for labor and the final good. In the absence of property rights to land, the return to land is zero and workers in the rural sector receive their average product. Therefore, given (2), the inverse demand for labor in the rural sector is

$$
w_{t}^{R}=\left(A_{t}^{R} / L_{t}^{R}\right)^{1-\alpha},
$$

where $w_{t}^{R}$ is the wage rate of rural labor in period $t .^{25}$

\footnotetext{
${ }^{25}$ The modeling of the production side is based on two simplifying assumptions. First, capital is not an input in the production process and, second, the return to land is zero. Since the fundamental mechanism of the emergence
} 
The inverse demand for labor in the manufacturing sector, given (3), is

$$
w_{t}^{M}=A_{t}^{M},
$$

where $w_{t}^{M}$ is the wage rate of manufacturing labor in period $t$.

As follows from (5), the inverse demand for labor in the rural sector increases without bound as employment decreases in that sector. This, coupled with the finite productivity of labor in the manufacturing sector, implies that the rural sector will be operative in every period. The manufacturing sector, in contrast, will be operative if and only if labor productivity in this sector exceeds the marginal productivity of labor in the rural sector when the entire labor force is employed in the rural sector. Moreover, perfect labor mobility between the two sectors implies that the sectoral wage rates will be equal as long as both sectors are used in production.

The following lemma and its associated corollary, respectively, establish conditions on the level of manufacturing productivity and, equivalently, on the size of the working population under which the manufacturing technology becomes economically viable.

Lemma 1 (The Manufacturing Productivity Threshold for the Economic Viability of the Manufacturing Sector) There exists a threshold level of manufacturing productivity, $\hat{A}_{t}^{M}$, such that the manufacturing sector is economically viable in period $t$ if and only if

$$
A_{t}^{M} \geq\left(A_{t}^{R} / L_{t}\right)^{1-\alpha} \equiv \hat{A}^{M}\left(A_{t}^{R}, L_{t}\right) \equiv \hat{A}_{t}^{M}
$$

Proof. Follows from (5)-(6) and the perfect mobility of labor between sectors, which assures that workers will start gaining employment in the manufacturing sector if their productivity in that sector, $A_{t}^{M}$, is at least as high as their marginal productivity in the rural sector, $\left(A_{t}^{R} / L_{t}\right)^{1-\alpha}$, when the entire labor force, $L_{t}$, is employed in the rural sector.

Corollary 1 (The Population Threshold for the Economic Viability of the Manufacturing Sector) Given $A_{t}^{M}>0$, there exists a unique threshold size of the working population, $\hat{L}_{t}$, such that the manufacturing sector is economically viable in period $t$ if and only if

$$
L_{t} \geq\left(1 / A_{t}^{M}\right)^{\frac{1}{1-\alpha}} A_{t}^{R} \equiv \hat{L}\left(A_{t}^{R}, A_{t}^{M}\right) \equiv \hat{L}_{t} .
$$

Let $\theta_{t} \in(0,1]$ denote the fraction of the economy's labor force employed in the rural sector in period $t$, i.e., $\theta_{t} \equiv L_{t}^{R} / L_{t}$. As follows from Lemma 1 and depicted in Figure 2 , if $A_{t}^{M}<\hat{A}_{t}^{M}$, the

of sustained growth explored in this paper focuses on the role of knowledge accumulation, rather than that of capital accumulation, the absence of capital from the production process is a natural simplifying assumption. One could have assumed, alternatively, that the economy uses capital as a factor input in both sectors, is small and open to a world capital market where the interest rate is constant, and that land is collectively owned with the proceeds distributed lump sum to the population. In this case, the quantity of capital would be fixed so as to equalize its marginal product to the world interest rate, whereas the price of land would evolve to ensure that the total return on land (rent plus price appreciation) would also equal the world interest rate. Allowing for capital accumulation and property rights over land in a closed economy context would complicate the model to the point of intractability. 
entire labor force will be employed in the rural sector and the wage rate in the economy, $w_{t}$, will be the associated wage rate in the rural sector, $w_{t}^{R}$. However, if $A_{t}^{M} \geq \hat{A}_{t}^{M}$, the manufacturing sector will be operational and the perfect mobility of workers between sectors will assure that $w_{t}=w_{t}^{R}$ $=w_{t}^{M}$, and, therefore, that $A_{t}^{M}=\left(A_{t}^{R} / L_{t}^{R}\right)^{1-\alpha}$. Hence, the equilibrium allocation of labor between the rural and manufacturing sectors in period $t$, as described by $\theta_{t}$, is given by

$$
\theta_{t} \equiv L_{t}^{R} / L_{t}=\left\{\begin{array}{lll}
1 & \text { if } & A_{t}^{M}<\hat{A}_{t}^{M} \\
\left(\frac{1}{A_{t}^{M}}\right)^{\frac{1}{1-\alpha}} \frac{A_{t}^{R}}{L_{t}} & \text { if } & A_{t}^{M} \geq \hat{A}_{t}^{M}
\end{array}\right.
$$

and, as follows from (5) and (6), the equilibrium wage rate in the economy in period $t, w_{t}$, is

$$
w_{t}= \begin{cases}w_{t}^{R}=\left(\frac{A_{t}^{R}}{L_{t}}\right)^{1-\alpha} & \text { if } \quad A_{t}^{M}<\hat{A}_{t}^{M} \\ w_{t}^{M}=A_{t}^{M} & \text { if } \quad A_{t}^{M} \geq \hat{A}_{t}^{M} .\end{cases}
$$

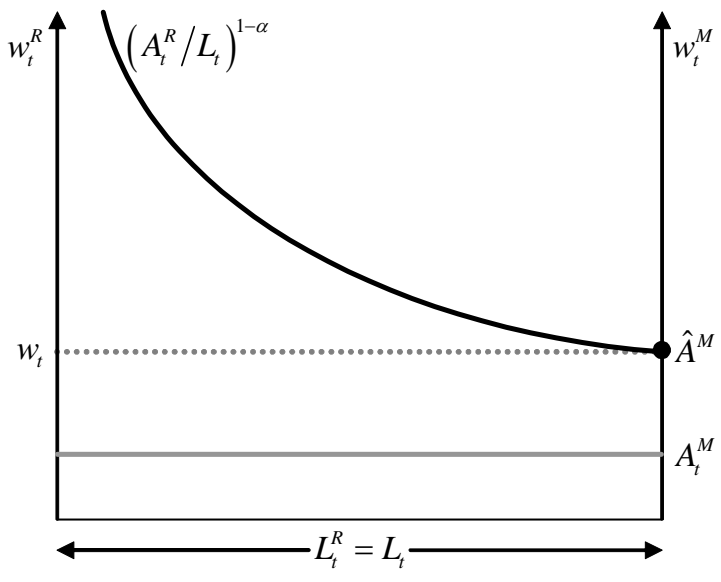

(a) The $A_{t}^{M}<\hat{A}_{t}^{M}$ Case

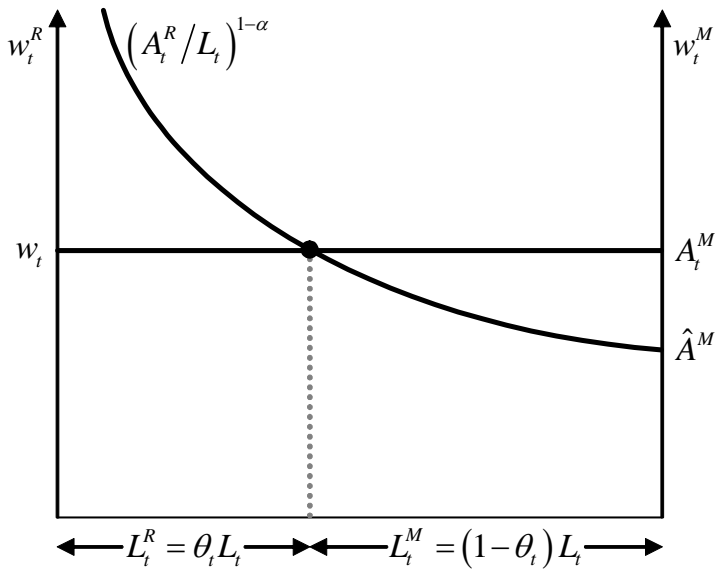

(b) The $A_{t}^{M} \geq \hat{A}_{t}^{M}$ Case

Figure 2: The Labor Market Equilibrium Conditional on the Level of Productivity of Labor in the Manufacturing Sector

Consistent with the historical path of economic development, where agriculture unequivocally precedes industry, it is assumed that the manufacturing sector is not economically viable in period 0. Namely,

$$
A_{0}^{M}<\left(A_{0}^{R} / L_{0}\right)^{1-\alpha}
$$




\subsection{Individuals}

In every period $t$, a generation comprising a continuum of $L_{t}$ economically identical individuals joins the labor force. Individuals, as described earlier, may exhibit variation in a given cultural trait (i.e., in their stance as a cultural conformist versus a nonconformist), thus, giving rise to a certain cultural composition of the generation in terms of this trait. As will become apparent, while the cultural composition of the labor force does not influence the economy's production activities in any manner within a given period, it does affect the dynamic path of the economy in the process of development. ${ }^{26}$

Reproduction occurs asexually and each individual, therefore, has a single parent. Members of generation $t$ live for two periods. In the first period of life (childhood), $t-1$, individuals are raised by their parents who face a fixed cost of child-rearing for every child in the household. ${ }^{27} \mathrm{In}$ the second period of life (parenthood), $t$, individuals are endowed with one unit of time, which they allocate entirely to labor force participation.

\subsubsection{Preferences and Constraints}

The preferences of members of generation $t$ (those born in period $t-1$ ) are defined over consumption as well as the number of their children. They are represented by the utility function

$$
u_{t}=\left(c_{t}\right)^{\gamma}\left(n_{t}\right)^{1-\gamma} ; \quad \gamma \in(0,1)
$$

where $c_{t}$ is consumption, and $n_{t}$ is the number of children of individual $t$. The individual's utility function is, therefore, strictly monotonically increasing and strictly quasi-concave, satisfying the conventional boundary conditions, which ensure that, for any positive level of income, there exists an interior solution to the utility maximization problem.

Let $\tau>0$ be the cost (in terms of the consumption good) faced by a member of generation $t$ for raising a child. Income from labor force participation is divided between expenditure on children (at a real cost of $\tau$ per child) and consumption. Hence, the budget constraint faced by a member of generation $t$ is

$$
c_{t}+\tau n_{t} \leq w_{t},
$$

where $w_{t}$ is the labor income of individual $t$, as given by (8).

\footnotetext{
${ }^{26}$ To be specific, cultural traits themselves have no effect of the individual sectoral productivity of the members of a given generation. However, the distribution of traits within a given generation affects the sectoral productivity of subsequent generations.

${ }^{27}$ This corresponds to the assumption that there exists some market, external to the economy, from where parents can simply purchase child-rearing services (at a fixed real cost per child) without having to incur any opportunity cost of time (in terms of labor force participation) for raising their children. An alternative modeling strategy based on a time cost associated with child-rearing would not affect the qualitative results of the model so long as technological progress reduces the amount of time required to raise a child.
} 


\subsubsection{Optimization}

Members of generation $t$ choose the number of their children and, therefore, their own consumption so as to maximize their utility subject to the budget constraint. Substituting (10) into (9), the optimization problem for a member of generation $t$ reduces to

$$
n_{t}=\arg \max \left\{\left(w_{t}-\tau n_{t}\right)^{\gamma}\left(n_{t}\right)^{1-\gamma}\right\}
$$

which, consistent with one of the fundamental features of a Malthusian environment, yields the optimal number of children for a member of generation $t$ as an increasing function of individual $t$ 's income. Specifically,

$$
n_{t}=\frac{1-\gamma}{\tau} w_{t}
$$

which, following (8), yields

$$
n_{t}=\left\{\begin{array}{lll}
\frac{1-\gamma}{\tau}\left(\frac{A_{t}^{R}}{L_{t}}\right)^{1-\alpha} & \text { if } & A_{t}^{M}<\hat{A}_{t}^{M} \\
\frac{1-\gamma}{\tau} A_{t}^{M} & \text { if } & A_{t}^{M} \geq \hat{A}_{t}^{M} .
\end{array}\right.
$$

\section{The Time Paths of the Macroeconomic Variables}

The time paths of the macroeconomic variables are captured by the dynamics of factor productivity in each of the rural and manufacturing sectors, $A_{t}^{R}$ and $A_{t}^{M}$, as well as the evolution of the size of the working population, $L_{t}$. The evolution of factor productivity in each sector is, in turn, determined by the accumulation of knowledge, and affected by the size and the cultural composition of the adult (working) population.

\subsection{The Dynamics of Knowledge}

In every period $t$, members of the adult generation in the economy develop new knowledge, which advances the productivity of society in two dimensions. First, new knowledge upgrades the existing production technologies, which expands society's production possibility frontier. Second, it permits improvements in the organization of society so that production can occur closer to the technological frontier. The process of knowledge creation is fueled by the size of the adult generation, $L_{t}$, via its effect on the supply of, the demand for, and the diffusion of ideas, as well as through its enhancement of trade and the division of labor. Furthermore, the knowledge creation process is complemented by the the degree of cultural heterogeneity in society, $\Omega$, which is represented by the product of the conformist and nonconformist fractions of the adult population, i.e., $\Omega=\omega(1-\omega)$. The higher is the cultural heterogeneity of the adult generation, the greater is the amount of new knowledge produced in the economy. 
The advancement in the stock of knowledge, $\Delta \kappa_{t}$, between its level in period $t, \kappa_{t}$, and its level in period $t+1, \kappa_{t+1}$, is, therefore,

$$
\Delta \kappa_{t} \equiv \kappa_{t+1}-\kappa_{t}=\kappa\left(L_{t} ; \Omega\right)
$$

where $\partial \kappa\left(L_{t} ; \Omega\right) / \partial L_{t}>0, \partial \kappa\left(L_{t} ; \Omega\right) / \partial \Omega>0, \partial^{2} \kappa\left(L_{t} ; \Omega\right) /\left(\partial L_{t} \partial \Omega\right) \geq 0$, and the initial stock of knowledge, $\kappa_{0}>0$, is given.

The change in the stock of knowledge between periods $t$ and $t+1, \Delta \kappa_{t}$, is assumed to be subject to diminishing marginal returns in the size of the economy's labor force in period $t$. In particular, it is taken to be of the form

$$
\Delta \kappa_{t}=\omega(1-\omega) L_{t}^{\lambda} ; \quad \lambda \in(0,1)
$$

\subsection{The Dynamics of Sectoral Productivity}

The level of productivity in each of the rural and manufacturing sectors, $A_{t}^{R}$ and $A_{t}^{M}$, is governed by the technological level in that sector as well as by the level of society-specific human capital (i.e., attitudes of trust, obedience, discipline, and social cohesion), which determines the extent of society's ability to take advantage of the technological frontier. Productivity in each sector is influenced positively by technological progress, which occurs via the incorporation of new knowledge into existing technologies and the application of new knowledge in improving the organization of society. Sectoral productivity, however, is influenced negatively by cultural nonconformism, which obstructs the transmission of society-specific human capital across generations.

The degree of nonconformism in society has an ambiguous effect on the level of productivity in each sector. On the one hand, nonconformism stimulates knowledge accumulation, advancing society's technological frontier (through either innovation or the adoption of existing technologies) and improving society's ability to operate closer to this frontier. On the other hand, it introduces disharmony in society, eroding society's ability to transmit its society-specific human capital from one generation to another. The evolution of factor productivity in each sector is, thus, subject to a fundamental trade-off whereby a larger fraction of nonconformists enhances productivity by contributing to knowledge creation, while diminishing productivity via its detrimental effect on the intergenerational transmission of society-specific human capital.

The dynamics of productivity in the rural and manufacturing sectors are governed by the same fundamental law of motion. In particular, productivity is enhanced by the creation of new knowledge, $\Delta \kappa_{t}$, and simultaneously diminished at a rate proportional to the fraction of nonconformists in society, $\omega$, reflecting the deleterious effect of nonconformism on the transmission of society-specific human capital. However, the advancement of knowledge, in general, and the invention and adoption of new technologies, in particular, are more complementary to productivity in the manufacturing sector as compared to the rural sector. ${ }^{28}$

\footnotetext{
${ }^{28}$ Knowledge is assumed to be a pure public good and is, therefore, nonrival and nonexcludable in terms of its
} 
The evolution of productivity in the manufacturing sector, between periods $t$ and $t+1$, as follows from (15), is determined by

$$
A_{t+1}^{M}=(1-\omega) A_{t}^{M}+\omega(1-\omega) L_{t}^{\lambda} A_{t}^{M} \equiv A^{M}\left(A_{t}^{M}, L_{t} ; \omega\right)
$$

where the initial level of manufacturing productivity, $A_{0}^{M}>0$, is given. In particular, $(1-\omega) A_{t}^{M}$ captures the erosion in productivity due to the disruptive effect of nonconformism on the transmission of society specific human capital, whereas $\omega(1-\omega) L_{t}^{\lambda} A_{t}^{M}$ captures the advancement in productivity due to the application of new knowledge to the existing level of technology. ${ }^{29}$

Similarly, the evolution of productivity in the rural sector, between periods $t$ and $t+1$, is determined by

$$
A_{t+1}^{R}=(1-\omega) A_{t}^{R}+\omega(1-\omega) L_{t}^{\lambda}\left(A_{t}^{R}\right)^{\beta} \equiv A^{R}\left(A_{t}^{R}, L_{t} ; \omega\right)
$$

where the initial level of rural productivity, $A_{0}^{R}>0$, is given, and

$$
\beta>0 \text { and } \quad \lambda+\beta<1
$$

assuring a smaller degree of complementarity between the advancement of the knowledge frontier and the existing stock of sector-specific productivity in the rural sector.

\subsection{The Dynamics of Population Size}

The size of the adult population (or labor force) in any period is determined by the size of the preceding generation and its fertility rate. As follows from (13), the adult population size evolves over time according to

$$
L_{t+1}=n_{t} L_{t}=\left\{\begin{array}{llll}
\frac{1-\gamma}{\tau}\left(A_{t}^{R}\right)^{1-\alpha} L_{t}^{\alpha} & \equiv L^{R}\left(A_{t}^{R}, L_{t}\right) & \text { if } \quad L_{t}<\hat{L}_{t} \\
\frac{1-\gamma}{\tau} A_{t}^{M} L_{t} & \equiv L^{M}\left(A_{t}^{M}, L_{t}\right) \quad \text { if } \quad L_{t} \geq \hat{L}_{t},
\end{array}\right.
$$

where the initial size of the adult population, $L_{0}>0$, is given.

Hence, as long as the manufacturing sector is not economically viable (i.e., the labor force $L_{t}<\hat{L}_{t}$, or manufacturing productivity $A_{t}^{M}<\hat{A}_{t}^{M}$ ), population dynamics are governed by the level of productivity in the rural sector as well as the size of the adult population. However, when both sectors are active, the labor market equilibrium ensures that population dynamics are governed by the level of productivity in the manufacturing sector and the size of the adult population.

\footnotetext{
applicability in the rural versus manufacturing sectors.

${ }^{29}$ As will become apparent, given the initial conditions of economies, TFP increases monotonically in the process of development.
} 


\section{The Process of Development}

This section examines the role of cultural factors in determining the characteristics of the Malthusian equilibrium and the timing of the take-off from an epoch of Malthusian stagnation to a state of sustained economic growth. ${ }^{30}$ The analysis demonstrates that, due to a greater efficiency in the intergenerational transmission of society-specific human capital, a society that is predominantly characterized by cultural assimilation flourishes in the Malthusian regime, benefiting from a more advanced agricultural technology and sustaining a higher population density. However, the associated lack of cultural diffusion delays the advancement of knowledge in this economy, hindering its ability to shift to an industrial technology and, thereby, escape Malthusian stagnation to enter a state of sustained economic growth.

The process of economic development, given the fraction $\omega$ of nonconformists in society as defined in (1), is fully determined by a sequence $\left\{A_{t}^{R}, A_{t}^{M}, L_{t} ; \omega\right\}_{t=0}^{\infty}$ that governs the evolution of the productivity in the rural sector, $A_{t}^{R}$, the productivity in the manufacturing sector, $A_{t}^{M}$, and the size of adult population, $L_{t}$. Specifically, noting (16), (17) and (18), the dynamic path of the economy is given by

$$
\left\{\begin{array}{l}
L_{t+1}=\left\{\begin{array}{c}
L^{R}\left(A_{t}^{R}, L_{t}\right) \quad \text { if } \quad L_{t}<\hat{L}\left(A_{t}^{R}, A_{t}^{M}\right) \\
L^{M}\left(A_{t}^{M}, L_{t}\right) \quad \text { if } \quad L_{t} \geq \hat{L}\left(A_{t}^{R}, A_{t}^{M}\right) ;
\end{array}\right. \\
A_{t+1}^{R}=A^{R}\left(A_{t}^{R}, L_{t} ; \omega\right) ; \\
A_{t+1}^{M}=A^{M}\left(A_{t}^{M}, L_{t} ; \omega\right),
\end{array}\right.
$$

where, consistent with the process of development, the initial conditions, $\left(A_{0}^{R}, A_{0}^{M}, L_{0}\right)$, are set to satisfy assumption (A1).

\subsection{The Dynamical System}

The global analysis of the evolution of the economy from the agricultural to the industrial regime is based on phase diagrams that describe the evolution of the system within the Malthusian epoch as well as its endogenous transition to an industrialized economy. The analysis underlines the role of the degree of cultural nonconformism in determining the characteristics of the Malthusian equilibrium and the timing of the economy's take-off to an industrial mode of production.

\footnotetext{
${ }^{30}$ Since reversals in economic performance are historically observed in the relatively earlier industrialization of economies that under-performed in the pre-industrial stage of development, the analysis here focuses on the forces that brought about industrialization, rather than the subsequent forces that led to the demographic transition and the emergence of the modern growth regime. Clearly, one could employ the methodology advanced by Galor and Weil (2000) and Galor (2005) and, thereby, generate the entire developmental path from Malthusian stagnation to the demographic transition and beyond. This additional complication, however, will not generate any new insights on the role of cultural factors in bringing about historical reversals in economic performance.
} 
The phase diagrams, depicted in Figures 3-4, describe the evolution of the system in the $\left(A_{t}^{R}, L_{t}\right)$ plane, conditional on the level of $A_{t}^{M}$. The evolution of $A_{t}^{M}$ generates a phase transition of the dynamical system and brings about a qualitative change that is associated with industrialization and the take-off to a state of sustained economic growth.

Each of the phase diagrams is based on three geometric elements that are instrumental for the determination of motion within the system: the Conditional Malthusian Frontier, which separates the regions in which the economy is agricultural from those where it is industrial; the $A A$ locus, which denotes the set of all pairs $\left(A_{t}^{R}, L_{t}\right)$ for which the productivity in the rural sector is constant; and the $L L$ locus, which denotes the set of all pairs for which, conditional on the latency of the manufacturing sector, the size of the adult population is constant.

\subsubsection{The Conditional Malthusian Frontier}

The Conditional Malthusian Frontier is a geometric locus, in $\left(A_{t}^{R}, L_{t}\right)$ space, that separates the regions where the economy is exclusively agricultural from those where it is industrial as well. Once the economy's trajectory crosses this frontier, industrialization takes place.

Let the Conditional Malthusian Frontier be the set of all pairs $\left(A_{t}^{R}, L_{t}\right)$ such that, for a given level of manufacturing productivity, $A_{t}^{M}$, the entrepreneurs in the economy are indifferent as to whether to operate the manufacturing sector or not. Following Corollary 1, the Conditional Malthusian Frontier, $M M_{\mid A_{t}^{M}}$, as depicted in Figures 3-4, is

$$
M M_{\mid A_{t}^{M}} \equiv\left\{\left(A_{t}^{R}, L_{t}\right): L_{t}=\hat{L}\left(A_{t}^{R}, A_{t}^{M}\right)\right\}
$$

Lemma 2 (The Properties of the Conditional Malthusian Frontier) If $\left(A_{t}^{R}, L_{t}\right) \in M M_{\mid A_{t}^{M}}$, then along the $M M_{\mid A_{t}^{M}}$ frontier,

$$
L_{t}=\left(1 / A_{t}^{M}\right)^{\frac{1}{1-\alpha}} A_{t}^{R} \equiv \hat{L}\left(A_{t}^{R}, A_{t}^{M}\right)
$$

where $\partial \hat{L}\left(A_{t}^{R}, A_{t}^{M}\right) / \partial A_{t}^{R}>0$, and $\partial \hat{L}\left(A_{t}^{R}, A_{t}^{M}\right) / \partial A_{t}^{M}<0$.

Proof. Follows immediately from (20), Corollary 1, and differentiation.

The Conditional Malthusian Frontier is, therefore, an upward sloping ray from the origin in $\left(A_{t}^{R}, L_{t}\right)$ space where, as follows from Corollary 1, the region strictly below the frontier is associated with production using only the rural technology and the region (weakly) above the frontier is associated with both industrial and agricultural production. Furthermore, the frontier rotates clockwise in $\left(A_{t}^{R}, L_{t}\right)$ space as $A_{t}^{M}$ increases in the process of development.

Lemma 3 (The Dynamics of Population Size with respect to the Conditional Malthusian Frontier) Given $A_{t}^{R}>0$ and $A_{t}^{M}>0$, for all $L_{t} \geq \hat{L}\left(A_{t}^{R}, A_{t}^{M}\right)$,

$$
L_{t+1}-L_{t} \gtreqless 0 \quad \text { if and only if } \quad A_{t}^{M} \gtreqless \frac{\tau}{1-\gamma} \text {. }
$$


Proof. Follows immediately from (18).

Hence, if the manufacturing sector is operational, (i.e., if the economy is in the region above the $M M_{\mid A_{t}^{M}}$ frontier in $\left(A_{t}^{R}, L_{t}\right)$ space), the evolution of the size of the adult population depends on the level of $A_{t}^{M}$ relative to a critical level, $\tau /(1-\gamma)$. In particular, when manufacturing productivity is below the threshold, $\tau /(1-\gamma)$, the wage rate in the economy is too low to sustain fertility beyond replacement so the adult population declines in size over time, whereas, if $A_{t}^{M}$ is above the critical threshold, then the wage rate is high enough to maintain fertility above the replacement level so the size of the adult population increases over time.

\subsubsection{The $A A$ Locus}

Let the $A A$ locus be the set of all pairs $\left(A_{t}^{R}, L_{t}\right)$ such that the level of rural productivity, $A_{t}^{R}$, is in a steady state:

$$
A A \equiv\left\{\left(A_{t}^{R}, L_{t}\right): A_{t+1}^{R}-A_{t}^{R}=0\right\}
$$

Lemma 4 (The Properties of the AA Locus) Under (A2), if $\left(A_{t}^{R}, L_{t}\right) \in A A$, then along the $A A$ locus,

$$
L_{t}=\left(\frac{1}{1-\omega}\right)^{\frac{1}{\lambda}}\left(A_{t}^{R}\right)^{\frac{1-\beta}{\lambda}} \equiv L^{A A}\left(A_{t}^{R} ; \omega\right),
$$

where $\partial L^{A A}\left(A_{t}^{R} ; \omega\right) / \partial A_{t}^{R}>0, \partial^{2} L^{A A}\left(A_{t}^{R} ; \omega\right) /\left(\partial A_{t}^{R}\right)^{2}>0$, and $\partial L^{A A}\left(A_{t}^{R} ; \omega\right) / \partial \omega>0$.

Proof. Noting (21), the functional form of $L^{A A}\left(A_{t}^{R} ; \omega\right)$ is obtained from the algebraic manipulation of (17) under $A_{t+1}^{R}=A_{t}^{R}$. The remainder follows directly from differentiation, while observing assumption (A2).

Corollary 2 (The Dynamics of Rural Productivity with respect to the AA Locus) Given $A_{t}^{R}>0$ and $\omega \in(0,1)$,

$$
A_{t+1}^{R}-A_{t}^{R} \gtreqless 0 \quad \text { if and only if } \quad L_{t} \gtreqless L^{A A}\left(A_{t}^{R} ; \omega\right) .
$$

Hence, the $A A$ locus, as depicted in Figures 3-4, is a strictly convex, upward sloping curve from the origin in $\left(A_{t}^{R}, L_{t}\right)$ space. Further, an increase in $\omega$ pushes the locus closer towards the $L_{t}$-axis. Moreover, $A_{t}^{R}$ grows over time above the $A A$ locus (i.e., for values of $L_{t}$ that, for a given $A_{t}^{R}$, are above the steady-state level), since the adult population here is sufficiently large to ensure that the associated advancement of the knowledge frontier fosters technology accumulation beyond the eroding forces of cultural nonconformism on productivity. Below the $A A$ locus (i.e., for values of $L_{t}$ that, for a given $A_{t}^{R}$, are below the steady-state level), the advancement of the knowledge frontier is not sufficient to overcome the eroding effects of nonconformism on productivity, so $A_{t}^{R}$ falls over time. 


\subsubsection{The $L L$ Locus}

Let the $L L$ locus be the set of all pairs $\left(A_{t}^{R}, L_{t}\right)$ such that, conditional on the latency of the manufacturing sector, the size of the adult population, $L_{t}$, is in a steady state:

$$
L L \equiv\left\{\left(A_{t}^{R}, L_{t}\right): L_{t+1}-L_{t}=0 \mid L_{t}<\hat{L}\left(A_{t}^{R}, A_{t}^{M}\right)\right\}
$$

Lemma 5 (The Properties of the LL Locus) If $\left(A_{t}^{R}, L_{t}\right) \in L L$, then along the LL locus,

$$
L_{t}=\left(\frac{1-\gamma}{\tau}\right)^{\frac{1}{1-\alpha}} A_{t}^{R} \equiv L^{L L}\left(A_{t}^{R}\right)
$$

where $d L_{t}^{L L} / d A_{t}^{R}>0$, and $d^{2} L_{t}^{L L} /\left(d A_{t}^{R}\right)^{2}=0$.

Proof. Noting (22), the functional form of $L^{L L}\left(A_{t}^{R}\right)$ is obtained from the algebraic manipulation of (18) under $L_{t+1}=L_{t}$. The remainder follows immediately from differentiation.

Corollary 3 (The Dynamics of Population Size with respect to the LL Locus) Given $A_{t}^{R}>0$ and $A_{t}^{M}>0$, for all $L_{t}<\hat{L}\left(A_{t}^{R}, A_{t}^{M}\right)$,

$$
L_{t+1}-L_{t} \lesseqgtr 0 \quad \text { if and only if } L_{t} \gtreqless L^{L L}\left(A_{t}^{R}\right) \text {. }
$$

Hence, the $L L$ locus, as depicted in Figures 3-4, is an upward sloping ray from the origin in $\left(A_{t}^{R}, L_{t}\right)$ space. $L_{t}$ grows over time below the $L L$ locus since a sufficiently high wage rate, that results from a population that is smaller than the steady-state level, permits fertility to be above replacement. $L_{t}$ declines over time above the $L L$ locus since a sufficiently low wage rate, resulting from a population that is larger than the steady-state level, dictates the fertility rate to be below the replacement level. The position of the $L L$ locus, in $\left(A_{t}^{R}, L_{t}\right)$ space, relative to the Conditional Malthusian Frontier, $M M_{\mid A_{t}^{M}}$, is established in the following lemma.

Lemma 6 (The Position of the LL Locus relative to the Conditional Malthusian Frontier) Given $A_{t}^{M}>0$, for all $A_{t}^{R}$ such that $\left(A_{t}^{R}, \hat{L}\left(A_{t}^{R}, A_{t}^{M}\right)\right) \in M M_{\mid A_{t}^{M}}$ and $\left(A_{t}^{R}, L^{L L}\left(A_{t}^{R}\right)\right) \in L L$,

$$
\hat{L}\left(A_{t}^{R}, A_{t}^{M}\right) \gtreqless L^{L L}\left(A_{t}^{R}\right) \quad \text { if and only if } \quad A_{t}^{M} \lesseqgtr \frac{\tau}{1-\gamma} \text {. }
$$

Proof. Follows from comparing the functional forms of $\hat{L}\left(A_{t}^{R}, A_{t}^{M}\right)$ and $L^{L L}\left(A_{t}^{R}\right)$, as specified in Corollary 1 and Lemma 5, respectively.

Thus, for $A_{t}^{M}<\tau /(1-\gamma)$, the Conditional Malthusian Frontier, $M M_{\mid A_{t}^{M}}$, is located above the $L L$ locus. However, the clockwise rotation of $M M_{\mid A_{t}^{M}}$, propelled by the growth of $A_{t}^{M}$ in the process of development, eventually causes the two loci to coincide when $A_{t}^{M}=\tau /(1-\gamma)$, and the Conditional Malthusian Frontier, $M M_{\mid A_{t}^{M}}$, subsequently drops below the $L L$ locus. 
The critical level of $A_{t}^{M}$, established in Lemma 3, that determines whether the size of adult population in the region above the Conditional Malthusian Frontier is growing or declining over time, therefore, also governs the position of $M M_{\mid A_{t}^{M}}$ relative to the $L L$ locus. As such, the growth of $A_{t}^{M}$ through the critical level, $\tau /(1-\gamma)$, instigates a permanent change in the qualitative nature of the system with respect to the global dynamics of the size of the adult population. This change reflects the transition of the system from the Malthusian to the Post-Malthusian regime and is summarized in the following lemma.

Lemma 7 (The Dynamics of Population Size with respect to the LL Locus and the Conditional Malthusian Frontier) Given $A_{t}^{M}>0$, for all $A_{t}^{R}>0$,

1. If $A_{t}^{M}<\frac{\tau}{1-\gamma}$, then

the Conditional Malthusian Frontier is above the LL locus, i.e.,

$$
\hat{L}\left(A_{t}^{R}, A_{t}^{M}\right)>L^{L L}\left(A_{t}^{R}\right)
$$

and

$$
L_{t+1}-L_{t}\left\{\begin{array}{lll}
<0 & \text { if } & L_{t}>L^{L L}\left(A_{t}^{R}\right) \\
=0 & \text { if } & L_{t}=L^{L L}\left(A_{t}^{R}\right) \\
>0 & \text { if } & L_{t}<L^{L L}\left(A_{t}^{R}\right)
\end{array}\right.
$$

2. If $A_{t}^{M}>\frac{\tau}{1-\gamma}$, then

the Conditional Malthusian Frontier is below the LL locus, i.e.,

$$
\hat{L}\left(A_{t}^{R}, A_{t}^{M}\right)<L^{L L}\left(A_{t}^{R}\right)
$$

and, for all $L_{t}$,

$$
L_{t+1}-L_{t}>0
$$

Proof. Part (1) follows immediately from Lemmas 3 and 6, and Corollary 3. Part (2) follows from the same results, while observing that above the Conditional Malthusian Frontier, $L_{t+1}-L_{t}>0$ if $A_{t}^{M}>\tau /(1-\gamma)$ and if $L_{t}$ is below the $L L$ locus.

\subsubsection{The Phase Diagrams}

The evolution of economic activity in the agricultural stage of development and in the transition to the industrial stage is depicted in the phase diagrams in Figures 3-4. Figure 3 depicts early stages of development where the economy is agricultural and characterized by Malthusian dynamics, whereas 
Figure 4 depicts the endogenous take-off to an industrial economy, characterized by an acceleration in the growth rates of output per worker and population.

The Agricultural Stage of Development The dynamical system in the agricultural stage of development, when productivity in the (latent) manufacturing sector, $A_{t}^{M}$, is below the critical level, $\tau /(1-\gamma)$, is depicted in Figure 3 .

As established in Lemma 7, the $M M_{\mid A_{t}^{M}}$ frontier, in this stage, resides above the $L L$ locus and the dynamical system is characterized by a globally stable conditional Malthusian steady-state equilibrium, $\left(A_{s s}^{R}, L_{s s}\right)$, located at the point of intersection of the $A A$ and $L L$ loci. It follows from the functional forms of $L^{A A}\left(A_{t}^{R} ; \omega\right)$ and $L^{L L}\left(A_{t}^{R}\right)$, specified in Lemmas 4 and 5 , respectively, that the Malthusian steady-state values of productivity in the rural sector, $A_{s s}^{R}$, and the size of the adult population, $L_{s s}$, are

$$
\begin{aligned}
& A_{s s}^{R}=\left[\left(\frac{1-\gamma}{\tau}\right)^{\frac{\lambda}{1-\alpha}}(1-\omega)\right]^{\frac{1}{1-\lambda-\beta}} \equiv A_{s s}^{R}(\omega) \\
& L_{s s}=\left[\left(\frac{1-\gamma}{\tau}\right)^{\frac{1-\beta}{1-\alpha}}(1-\omega)\right]^{\frac{1}{1-\lambda-\beta}} \equiv L_{s s}(\omega) .
\end{aligned}
$$

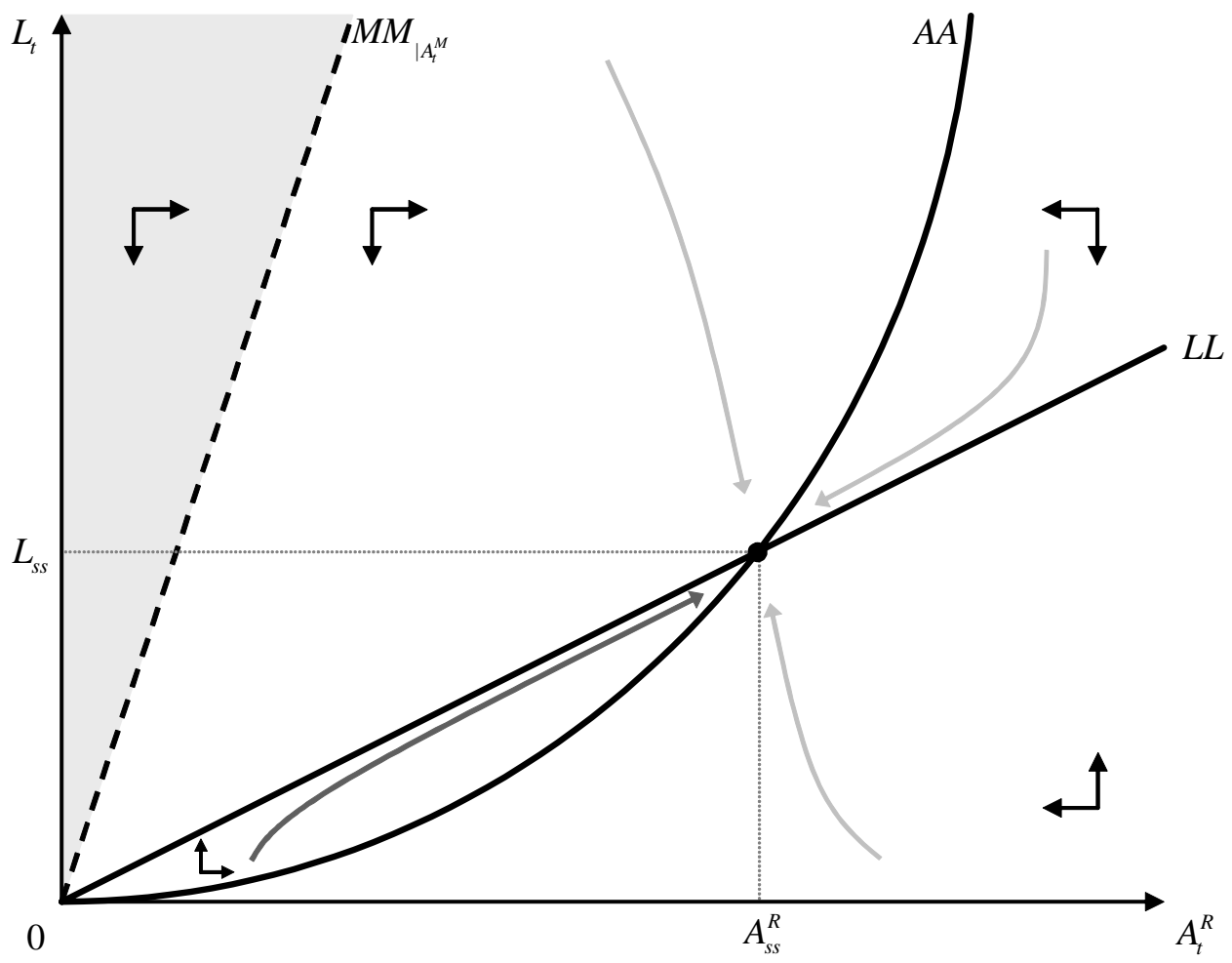

Figure 3: The Agricultural Stage of Development 
The dynamical system gravitates towards the steady-state equilibrium in a conventional Malthusian fashion. ${ }^{31}$ Specifically, in the region above the $L L$ locus but below $M M_{\mid A_{t}^{M}}$, the adult population (employed exclusively in the rural sector) is sufficiently large and, hence, the wage rate sufficiently small such that fertility is at sub-replacement levels. Thus, as depicted in the phase diagram, the adult population in this region declines in size over time. However, below the $L L$ locus the adult population is sufficiently small and the rural wage rate is, therefore, large enough to ensure that the fertility rate is above replacement, implying that the adult population in this region grows in size over time. Finally, in the region above $M M_{\mid A_{t}^{M}}$, it follows from Lemma 3 that the size of the adult population falls over time, which eventually drops the economy below the Conditional Malthusian Frontier. The industrial mode of production is, therefore, not sustainable in this stage of development, with the economy ultimately converging to an agricultural regime, characterized by a Malthusian equilibrium.

Given the discrete nature of the dynamical system, the trajectories implied by the phase diagram in Figure 3 approximate the actual dynamic paths only if both state variables evolve monotonically over time. The actual system, however, may be characterized by oscillatory convergence to the conditional Malthusian steady-state equilibrium if at least one of the eigenvalues of the system's Jacobian matrix is negative (Galor, 2007). The trajectories in Figure 3 are, thus, drawn under the assumption that the parametric condition in Lemma 8 holds so as to ensure that the conditional dynamical system is locally nonoscillatory in the vicinity of the conditional Malthusian steady-state. However, the qualitative aspects of analysis would not be altered even if oscillations were to characterize the evolution of the Malthusian economy towards its steady-state, since this a feature that appears to be present during the Malthusian epoch. ${ }^{32}$

The stability properties of the conditional steady-state equilibrium, $\left(A_{s s}^{R}, L_{s s}\right)$, are formally established in the following lemma by examining the eigenvalues of the Jacobian matrix of the conditional dynamical system evaluated at the steady-state equilibrium.

Lemma 8 (The Local Stability Properties of the Conditional Malthusian Steady-State) If (A2) is satisfied and $A_{t}^{M}<\tau /(1-\gamma)$, then the conditional steady-state equilibrium, $\left(A_{s s}^{R}, L_{s s}\right)$, of the dynamical system in (19) is:

\section{1. locally asymptotically stable; and}

2. characterized by the local monotonic evolution of both state variables, $A_{t}^{R}$ and $L_{t}$, if and only if the Jacobian matrix,

$$
J\left(A_{s s}^{R}, L_{s s}\right)=\left[\begin{array}{cc}
\partial A^{R}\left(A_{s s}^{R}, L_{s s} ; \omega\right) / \partial A_{t}^{R} & \partial A^{R}\left(A_{s s}^{R}, L_{s s} ; \omega\right) / \partial L_{t} \\
\partial L^{R}\left(A_{s s}^{R}, L_{s s}\right) / \partial A_{t}^{R} & \partial L^{R}\left(A_{s s}^{R}, L_{s s}\right) / \partial L_{t}
\end{array}\right],
$$

\footnotetext{
${ }^{31}$ The system has, in addition, an unstable trivial steady-state located at the origin of $\left(A_{t}^{R}, L_{t}\right)$ space. Given $A_{0}^{R}>0$ and $L_{0}>0$, however, the non-trivial steady-state equilibrium is globally stable.

${ }^{32}$ See, for example, Galor (2005) and Lagerlöf (2006).
} 
has eigenvalues that are real and positive, i.e., if and only if

$$
\omega<\frac{\alpha}{\lambda+\alpha(1-\lambda-\beta)} .
$$

Proof. See Appendix.

The Industrial Stage of Development The dynamical system in the industrial stage of development, when manufacturing productivity, $A_{t}^{M}$, is above the critical level, $\tau /(1-\gamma)$, is depicted in Figure 4.

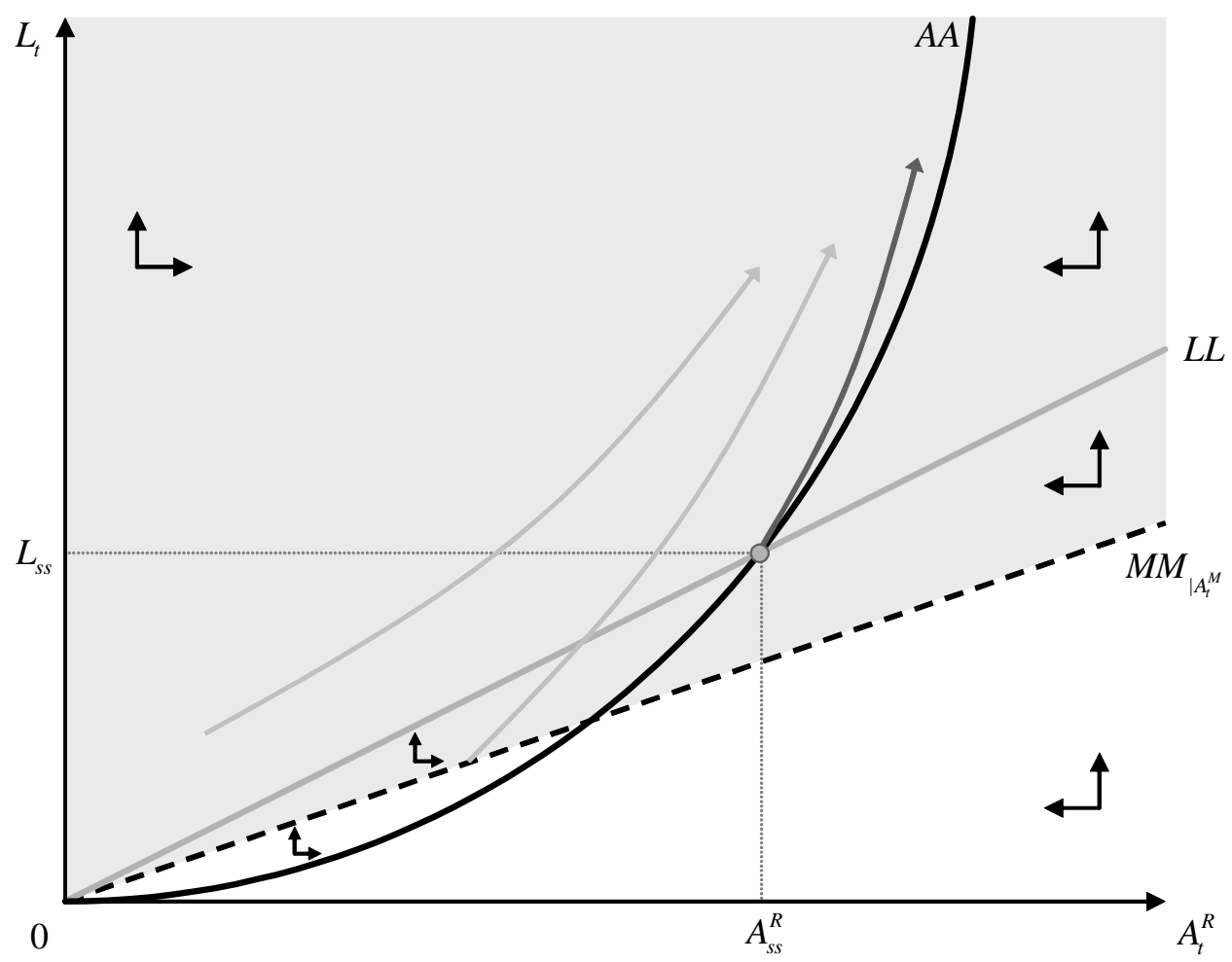

Figure 4: Industrialization and the Take-off

As established in Lemma 7, the $M M_{\mid A_{t}^{M}}$ frontier, in this stage, resides below the $L L$ locus and the dynamical system changes qualitatively in relation to its characteristics in the agricultural stage. The wage rate increases over time, permitting a continuous increase in the size of the adult population, along with an increase in the growth rate of productivity and output per worker.

The Transition from Agriculture to Industry The transition from agriculture to industry in the process of development is brought about by the growth of manufacturing productivity from its initial level below the critical threshold, $\tau /(1-\gamma)$, as depicted in Figure 3, to a level beyond this threshold, as depicted in Figure 4. 
The transition from agriculture to industry, therefore, requires that the economy starts with a mode of production that is exclusively agricultural. Hence, the initial level of manufacturing productivity is assumed to satisfy

$$
A_{0}^{M}<\tau /(1-\gamma)
$$

Furthermore, to assure that industrial production ultimately becomes economically viable, it is sufficient to assume that (latent) manufacturing productivity grows monotonically and eventually exceeds the critical magnitude, $\tau /(1-\gamma)$.

Let $g_{t+1}$ denote the rate of productivity growth in the manufacturing sector between periods $t$ and $t+1$. It follows directly from (16) that

$$
g_{t+1} \equiv \frac{A_{t+1}^{M}-A_{t}^{M}}{A_{t}^{M}}=\omega\left[(1-\omega) L_{t}^{\lambda}-1\right] \equiv g\left(L_{t}, \omega\right) .
$$

In particular, noting (24), the improvement in productivity that takes place in the (latent) manufacturing sector between any two adjacent periods at the conditional Malthusian steady-state equilibrium is

$$
g\left(L_{s s}(\omega), \omega\right)=\omega\left\{\left[\left(\frac{1-\gamma}{\tau}\right)^{\frac{\lambda}{1-\alpha}}(1-\omega)\right]^{\frac{1-\beta}{1-\lambda-\beta}}-1\right\} \equiv g_{s s}(\omega)
$$

where $g_{s s}(0)=0$ and $g_{s s}(1)=-1$.

Lemma 9 (The Condition for Positivity of the Growth Rate of Manufacturing Productivity at the Conditional Malthusian Steady-State) There exists some $\omega \in(0,1)$ such that

$$
g_{s s}(\omega)>0 \text { if and only if } \gamma+\tau<1
$$

Proof. Necessity follows immediately from observing that, given $\omega \in(0,1)$, the positivity of $g_{s s}$ implies that $(1-\gamma) / \tau>1$. For sufficiency, given $(1-\gamma) / \tau>1$, the proof follows trivially from the continuity of $g_{s s}$ as $\omega$ approaches 0 from above.

Following Lemma 9, in order to permit society's transition to an industrial economy for at least some cultural compositions of society, $\omega$, the sum of the parameters $\gamma$ and $\tau$ is restricted so as to ensure a positive rate of productivity growth in the (latent) manufacturing sector at the conditional Malthusian steady-state equilibrium, i.e.,

$$
\gamma+\tau<1
$$

Lemma 10 (The Properties of the Growth Rate of Manufacturing Productivity at the Conditional Malthusian Steady-State) 
1. Under (A4), there exists a unique $\hat{\omega} \in(0,1)$ such that

$$
g_{s s}(\omega) \gtreqless 0 \quad \text { if and only if } \omega \lesseqgtr \hat{\omega} \text {; }
$$

2. Under (A2) and (A4), $d g_{s s}(0) / d \omega>0$, and there exists a unique $\tilde{\omega} \in(0,1)$ such that

$$
d g_{s s}(\tilde{\omega}) / d \omega<0 \quad \text { and } \quad d^{2} g_{s s}(\omega) /(d \omega)^{2} \lesseqgtr 0 \quad \text { if and only if } \omega \lesseqgtr \tilde{\omega} \text {, }
$$

Proof. See Appendix.

Corollary 4 (The Fraction of Cultural Nonconformists that Maximizes the Growth Rate of Manufacturing Productivity at the Conditional Malthusian Steady-State) Under (A2) and (A4), there exists a unique $\omega^{*} \in(0,1)$ such that

$$
d g_{s s}(\omega) / d \omega \gtreqless 0 \quad \text { if and only if } \omega \lesseqgtr \omega^{*} \text {. }
$$

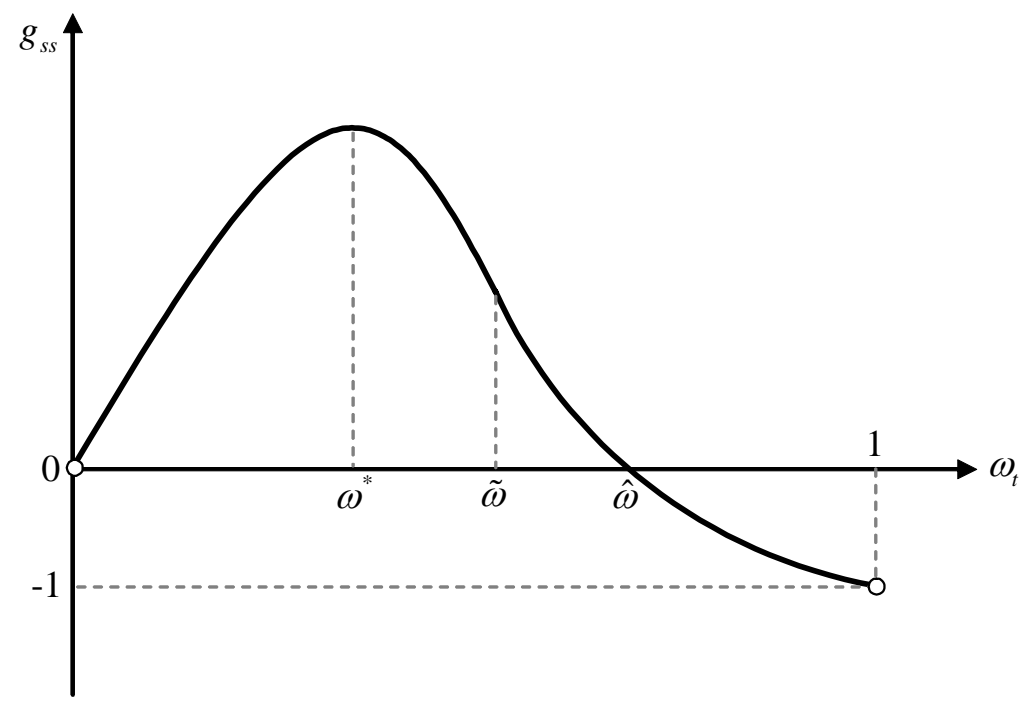

Figure 5: The Effect of the Fraction of Cultural Nonconformists on the Growth

Rate of Manufacturing Productivity at the Conditional Malthusian Steady-State

The growth rate of manufacturing productivity at the conditional Malthusian steady-state equilibrium, $g_{s s}$, has a unique interior root, $\hat{\omega}$, in the $(0,1)$ domain, and is positive (negative) for all values of $\omega$ below (respectively, above) the root. Furthermore, as depicted in Figure 5 , it has a hump-shaped relationship with the fraction of cultural nonconformists in the adult population. ${ }^{33}$ In particular, for a certain range of cultural compositions, i.e., for $\omega \in(0, \hat{\omega})$, the productivity in the

\footnotetext{
${ }^{33}$ Without loss of generality, Figure 5 has been drawn under the implicit assumption that $\tilde{\omega}<\hat{\omega}$. The general hump-shaped relationship between $g_{s s}$ and $\omega$, however, holds regardless of whether the value of $\omega$ at the inflection point, $\tilde{\omega}$, is below, above or equal to the root value, $\hat{\omega}$.
} 
(latent) manufacturing sector, at the conditional Malthusian steady-state equilibrium, increases monotonically over time, making industrialization ultimately inevitable.

\subsection{The Evolution of the Economy}

The evolution of the economy is characterized by an early epoch of Malthusian stagnation, where production is exclusively agricultural, and by an endogenous industrialization with a subsequent take-off to a state of sustained economic growth.

\subsubsection{The Agricultural Economy}

In early stages of development, the productivity in the (latent) manufacturing sector, $A_{t}^{M}$, is low (satisfying assumptions (A1) and (A3)), and only the rural sector is operative. The dynamical system, depicted in Figure 3, gravitates (monotonically or in Malthusian oscillations) towards a globally stable conditional steady-state equilibrium, $\left(A_{s s}^{R}, L_{s s}\right)$.

Since the adult population in this stage of development is employed exclusively in the rural

sector, it follows from (2) that the steady-state level of income per worker is $\left(A_{s s}^{R} / L_{s s}\right)^{1-\alpha}$. Using (23) and (24), the steady-state level of income per worker is given by

$$
y_{s s}=\left(\frac{\tau}{1-\gamma}\right)
$$

which reflects the well-established Malthusian property that the long-run level of income per capita is constant and independent of the level of technology. A higher level of productivity per worker is simply counter-balanced by a larger size of the working population.

\subsubsection{From Agriculture to Industry}

The transition from agriculture to industry in the process of development is brought about by the growth of productivity in the (latent) manufacturing sector. As manufacturing productivity increases, the Conditional Malthusian Frontier, $M M_{\mid A_{t}^{M}}$, rotates clockwise in the $\left(A_{t}^{R}, L_{t}\right)$ space of Figure 3. The level of productivity in the manufacturing sector ultimately surpasses the critical threshold, $\tau /(1-\gamma)$, which drops the Conditional Malthusian Frontier below the $L L$ locus, as depicted in Figure 4.

The dynamical system, in $\left(A_{t}^{R}, L_{t}\right)$ space, is no longer characterized by a globally stable conditional Malthusian steady-state. Specifically, the steady-state equilibrium ceases to act as an attractor as soon as trajectories cross the Conditional Malthusian Frontier and the manufacturing sector becomes active. The emergence of the manufacturing sector then places the economy on a dynamic path where the state variables, $A_{t}^{R}$ and $L_{t}$, grow endogenously over time, and the growth of manufacturing productivity drives the growth of income per worker. 


\subsection{Culture and Comparative Development}

The effect of culture on comparative development can be examined based on the effect of cultural composition on Malthusian equilibrium outcomes in the agricultural stage of development, and on the timing of industrialization and the take-off to a state of sustained economic growth.

Proposition 1 (The Effect of the Fraction of Cultural Nonconformists on the Equilibrium in the Agricultural Stage of Development) Under (A2), as long as the economy remains exclusively agricultural, an increase in the fraction of cultural nonconformists has an adverse effect on the steady-state levels of productivity in the rural sector and the size of the adult population, but has no effect on the steady-state level of income per capita, i.e., for all $\omega \in(0,1)$,

$$
\begin{aligned}
& d A_{s s}^{R} / d \omega<0 ; \quad d L_{s s} / d \omega<0 \\
& d y_{s s} / d \omega=0 .
\end{aligned}
$$

Proof. Follows from differentiating (23), (24) and (27) with respect to $\omega$, while noting (A2).

Geometrically, as depicted in Figure 6, a higher value of $\omega$ causes the $A A$ locus to reside closer to the $L_{t}$-axis in $\left(A_{t}^{R}, L_{t}\right)$ space, thereby, yielding lower steady-state levels of adult population size and rural productivity.

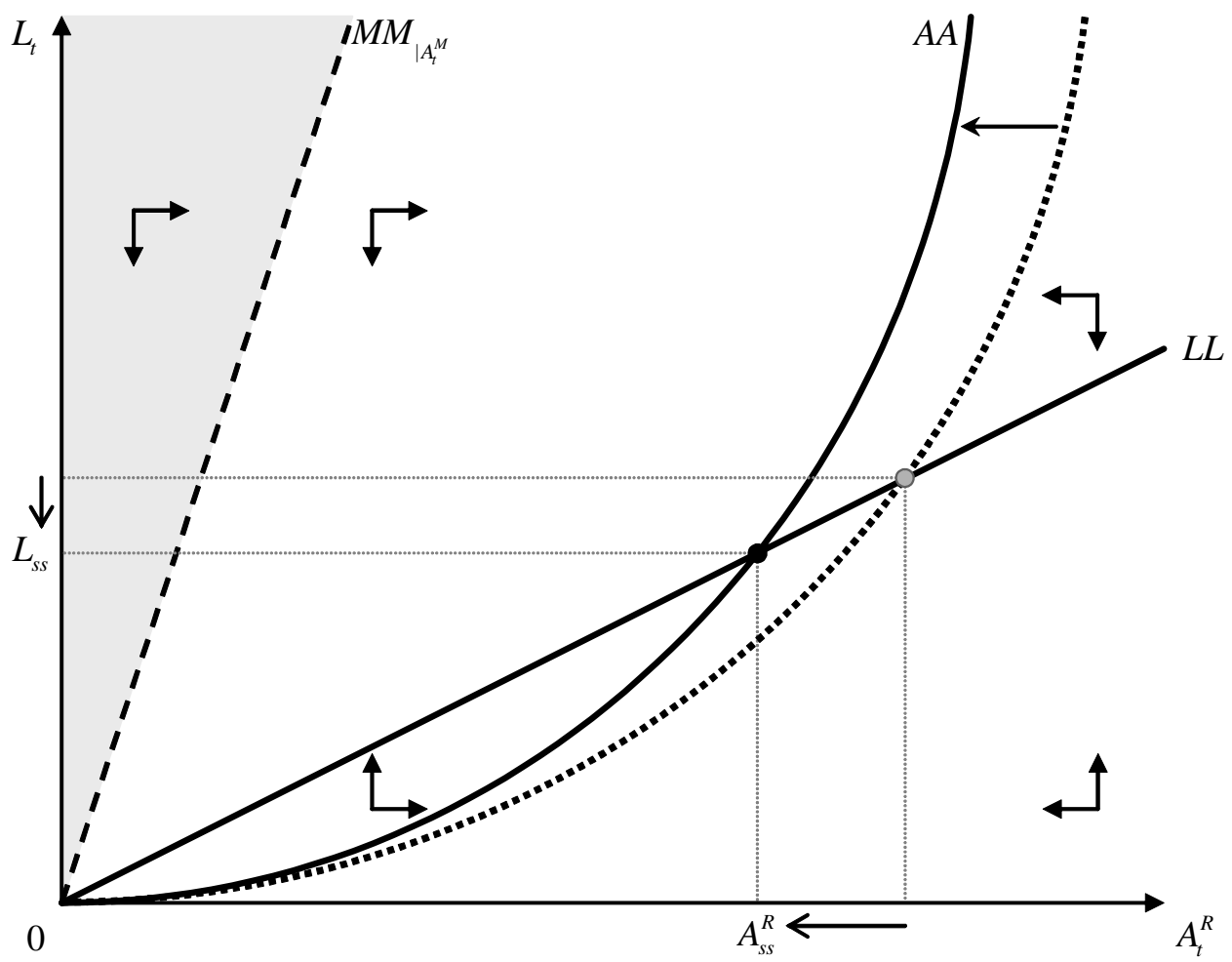

Figure 6: The Effect of an Increase in the Fraction of Cultural Nonconformists on the Malthusian Equilibrium in the Agricultural Stage of Development 
Therefore, an economy that is characterized by a relatively higher proportion of cultural nonconformists in its working population is also associated with a relatively inferior conditional Malthusian steady-state, at least in terms of the level of rural productivity per worker and the size of its working population. However, the long-run level of income per capita is unaffected by the higher prevalence of cultural nonconformism since the resulting lower level of productivity per worker is counter-balanced by a smaller size of the working population.

The inferiority of the conditional Malthusian steady-state in a society with a larger fraction of cultural nonconformists stems from the fact that the adverse effect of nonconformism on the transmission of society-specific human capital outweighs its beneficial role in the moderate advancement of rural productivity, via its contribution to cultural heterogeneity in the expansion of the knowledge frontier.

The prevalence of cultural nonconformism, however, also has an effect on the timing of industrialization and, thus, on the take-off to a state of sustained economic growth. This effect is summarized in the following proposition.

Proposition 2 (The Effect of the Fraction of Cultural Nonconformists on the Timing of Industrialization and the Take-off from Malthusian Stagnation) Consider an economy in a conditional Malthusian steady-state equilibrium. Under (A2) and (A4), an increase in the fraction of cultural nonconformists, as long as the fraction is not too large, has a beneficial effect on the timing of the adoption of industry and, thus, on the timing of the take-off from Malthusian stagnation, i.e.,

$$
d g_{s s} / d \omega \gtreqless 0 \text { if and only if } \omega \lesseqgtr \omega^{*} \text {. }
$$

Proof. Follows immediately from Corollary 4.

Hence, productivity growth in the (latent) manufacturing sector at the conditional Malthusian steady-state equilibrium is monotonically increasing in the nonconformist fraction of the adult population up to a critical level $\omega^{*}$, and monotonically decreasing thereafter.

The earlier take-off from the conditional Malthusian steady-state equilibrium by a society with a larger, but still moderate, fraction of cultural nonconformists stems from the fact that the beneficial effect of nonconformism on the advancement of knowledge, and, therefore, on the advancement of industrial productivity relative to that in agriculture, outweighs its eroding effect on the intergenerational transmission of society-specific human capital. In contrast, if the fraction of nonconformists is too large, an increase in the prevalence of nonconformism raises the flow of ideas but also increases the degree of anarchy in society, acutely disrupting the transmission of society-specific human capital. The rate at which new ideas are implemented and productivity is advanced in the economy is, therefore, diminished.

Following Propositions 1 and 2, variation in the moderate prevalence of cultural nonconformism across societies is associated with the phenomenon of overtaking. Specifically, a higher prevalence of nonconformism generates an inferior economic outcome in the agricultural stage of 
development, but ultimately stimulates an earlier industrialization and, thus, an earlier take-off to a state of sustained economic growth. As such, the cultural composition of societies can have a profound effect on their historical experience with regard to the process of development.

Corollary 5 (Cultural Nonconformism and Overtaking) Consider two societies indexed by $i \in$ $\{C, E\}$. Suppose that society $E$ is characterized by a higher prevalence of cultural nonconformism and that $\omega^{C}<\omega^{E}<\omega^{*}$, where $\omega^{i}$ is the fraction of cultural nonconformists in society $i$. Society $E$ will then be characterized by an inferior productivity in the Malthusian regime, but will overtake society $C$ via an earlier take-off into the industrial regime.

\subsection{Geography, Culture, and Comparative Development}

The effect of initial geographical conditions on comparative development can be examined based on the effects of geographical vulnerability to cultural diffusion on Malthusian equilibrium outcomes in the agricultural stage of development, and on the timing of industrialization and the take-off to a state of sustained economic growth.

Proposition 3 (The Effect of Geographical Vulnerability to Cultural Diffusion on the Equilibrium in the Agricultural Stage of Development) Under (A2), as long as the economy remains exclusively agricultural, an increase in geographical vulnerability to cultural diffusion has an adverse effect on the steady-state levels of productivity in the rural sector and the size of the working population, but has no effect on the steady-state level of income per capita, i.e., for all $\mu \in(0,1)$,

$$
\begin{aligned}
& d A_{s s}^{R} / d \mu<0 ; \quad d L_{s s} / d \mu<0 \\
& d y_{s s} / d \mu=0 .
\end{aligned}
$$

Proof. Follows immediately from Proposition 1, while noting that $\partial \omega / \partial \mu>0$ in (1).

Hence, an economy that is characterized by greater geographical vulnerability to foreign cultural influences, and, thus, by more cultural diffusion, is also associated with a relatively inferior conditional Malthusian steady-state, in terms of the level of rural productivity per worker and the size of its working population. This inferiority arises from the fact that greater geographical vulnerability to cultural diffusion results in a relatively higher prevalence of cultural nonconformism in society, with the adverse effect of nonconformism on the transmission of society-specific human capital outweighing its productive role in the moderate advancement of rural productivity through the expansion of the knowledge frontier. Nonetheless, the long-run level of income per capita is unaffected by greater geographical vulnerability since the resulting lower level of productivity per worker is accommodated by a smaller size of the working population.

The extent of geographical vulnerability to cultural diffusion, as a result of its influence on the fraction of cultural nonconformists, however, also has an effect on the timing of industrialization and, thus, the take-off to a state of sustained economic growth. This effect is summarized in the following proposition. 
Proposition 4 (The Effect of Geographical Vulnerability to Cultural Diffusion on the Timing of Industrialization and the Take-off from Malthusian Stagnation) Consider an economy in a conditional Malthusian steady-state equilibrium. Under (A2) and (A4), an increase in the geographical vulnerability to cultural diffusion, as long as the vulnerability is not too high, has a beneficial effect on the timing of the adoption of industry and, thus, on the timing of the take-off from Malthusian stagnation, i.e.,

$$
d g_{s s} / d \mu \gtreqless 0 \text { if and only if } \mu \lesseqgtr \mu^{*},
$$

where $\mu^{*}$ is implicitly given by $\omega\left(\mu^{*}, \sigma\right)=\omega^{*}$.

Proof. Follows immediately from Proposition 2, while noting that $\partial \omega / \partial \mu>0$ in (1).

Thus, productivity growth in the (latent) manufacturing sector at the conditional Malthusian steady-state equilibrium is monotonically increasing in geographical vulnerability to cultural diffusion up to a critical level $\mu^{*}$, and monotonically decreasing thereafter.

The earlier take-off from the conditional Malthusian steady-state by a society that has a higher but moderate geographical vulnerability to cultural diffusion, and, hence, possesses a higher prevalence of moderated nonconformism, stems from the fact that the adverse effect of nonconformism on the intergenerational transmission of society-specific human capital is outweighed by its beneficial effect on the advancement of knowledge, and, thus, on the advancement of industrial productivity relative to that in agriculture. However, if the degree of vulnerability to diffusion is too large, and, thus, the prevalence of nonconformism too high, an increase in vulnerability raises the degree of anarchy in society and, thereby, severely disrupts the transmission of society-specific human capital. Thus, while a higher degree of vulnerability to cultural diffusion increases the flow of new ideas, the rate at which these ideas are implemented and productivity is advanced in the economy is diminished.

Following Propositions 3 and 4, variation across societies over a moderate range in the degree of geographical vulnerability to cultural diffusion is associated with the phenomenon of overtaking in global economic development. In particular, a higher degree of geographical vulnerability generates an inferior economic outcome in the agricultural stage of development, but ultimately stimulates an earlier industrialization and, thus, an earlier take-off to a state of sustained economic growth. By influencing the cultural composition of societies throughout history, geography confers a profound effect on their experience with regard to the process of economic development.

Corollary 6 (Geographical Vulnerability to Cultural Diffusion and Overtaking). Consider two societies indexed by $i \in\{C, E\}$. Suppose that society $E$ is characterized by a higher geographical vulnerability to cultural diffusion, and, thus, a higher prevalence of cultural nonconformism, and that $\mu^{C}<\mu^{E}<\mu^{*}$, where $\mu^{i}$ is the degree of geographical vulnerability in society $i$. Society $E$ will then be characterized by a inferior productivity in the Malthusian regime, but will overtake society $C$ via an earlier take-off into the industrial regime. 


\section{Concluding Remarks}

This research argues that variations in the interplay between cultural assimilation and cultural diffusion played a significant role in giving rise to the differential patterns of economic development across the globe. Societies that were geographically less vulnerable to cultural diffusion, benefited from enhanced assimilation, lower cultural diversity and, thus, more intense accumulation of societyspecific human capital, flourishing in the technological paradigm that characterized the agricultural stage of development. However, the lack of cultural diffusion and its manifestation in cultural homogeneity and rigidity diminished the ability of these societies to adapt to a new technological paradigm, delaying the onset of their industrialization and, thus, their take-off to a state of sustained economic growth.

The superiority of societies that were geographically less vulnerable to cultural diffusion in early stages of development stems from the dominance of the beneficial effect of an uninterrupted process of cultural assimilation on the transmission of society-specific human capital over the adverse effect of cultural rigidity on the advancement of knowledge and its spillover to the agricultural technology. In comparison, the earlier take-off of societies that were more vulnerable to cultural diffusion, reflects the dominance of the beneficial effects of cultural diversity and flexibility on the advancement of the knowledge-intensive industrial technology, relative to its eroding effect on the accumulation of society-specific human capital.

Thus, in contrast to the cultural and institutional hypotheses, which posit a hierarchy of cultural and institutional attributes in terms of their conduciveness to innovation and their applicability towards an industrial take-off, the proposed theory suggests that the desirable degree of the relative prevalence of cultural assimilation versus cultural diffusion varies according to the stage of development. Enhanced cultural assimilation is optimal in the agricultural stage, but is detrimental for the take-off to the industrial stage. Therefore, while cultural traits themselves do not necessarily have a differential effect on the process of development, it is the variation in the relative strengths of the forces of cultural assimilation and cultural diffusion, which together determine the overall degree of heterogeneity in these traits, that is instrumental for comparative economic development.

The proposed theory elucidates how variation in the implementation of culture across societies can explain historical reversals in their economic performance during the course of the worldwide transition from agriculture to industry and can, in fact, be applied more generally to understand current and future reversals as the global frontier advances from one technological paradigm to another. ${ }^{34}$ Indeed, the trade-off between the benefits of enhanced cultural assimilation in the short-run and the costs of cultural rigidify in the long-run is analogous to the trade-off between sexual and asexual reproduction with respect to biological fitness. Asexual reproduction is beneficial in the short-run when the environment is relatively stable, while being costly in the long-run

\footnotetext{
${ }^{34}$ Brezis, Krugman, and Tsiddon (1993) attribute technological leapfrogging to the acquired comparative advantage (via learning by doing) of the current technological leaders in the use of the existing technologies.
} 
due to its elimination of genetic diversity amongst offspring, which may become critical for their adaptability and, thus, survivability in a gradually changing environment.

\section{Appendix}

Proof of Lemma 8. Under $A_{t}^{M}<\tau /(1-\gamma)$, the Jacobian matrix of the conditional dynamical system, comprised of (17) and (18), is given by

$$
\begin{aligned}
J\left(A_{t}^{R}, L_{t}\right) & =\left[\begin{array}{ll}
\partial A_{t+1}^{R} / \partial A_{t}^{R} & \partial A_{t+1}^{R} / \partial L_{t} \\
\partial L_{t+1} / \partial A_{t}^{R} & \partial L_{t+1} / \partial L_{t}
\end{array}\right] \\
& =\left[\begin{array}{cc}
(1-\omega)\left(1+\beta \omega \frac{\left(L_{t}\right)^{\lambda}}{\left(A_{t}^{R}\right)^{1-\beta}}\right) & \lambda \omega(1-\omega) \frac{\left(A_{t}^{R}\right)^{\beta}}{\left(L_{t}\right)^{1-\lambda}} \\
(1-\alpha)\left(\frac{1-\gamma}{\tau}\right)\left(\frac{L_{t}}{A_{t}^{R}}\right)^{\alpha} & \alpha\left(\frac{1-\gamma}{\tau}\right)\left(\frac{A_{t}^{R}}{L_{t}}\right)^{1-\alpha}
\end{array}\right],
\end{aligned}
$$

which, when evaluated at the conditional steady state given by (23) and (24), yields

$$
J\left(A_{s s}^{R}, L_{s s}\right)=\left[\begin{array}{cc}
1-\omega(1-\beta) & \lambda \omega\left(\frac{\tau}{1-\gamma}\right)^{\frac{1}{1-\alpha}} \\
(1-\alpha)\left(\frac{1-\gamma}{\tau}\right)^{\frac{1}{1-\alpha}} & \alpha
\end{array}\right] \equiv J_{s s} .
$$

It follows directly from (29) and (A2) that the trace of the matrix $J_{s s}$ is positive for any $\omega$, i.e.,

$$
\operatorname{Tr}\left(J_{s s}\right)=1-\omega(1-\beta)+\alpha>0, \forall \omega \in(0,1)
$$

Therefore, to establish that $\left(A_{s s}^{R}, L_{s s}\right)$ is a locally asymptotically stable node of the conditional dynamical system for any $\omega$, it suffices to show that, for all $\omega \in(0,1)$, the following restriction holds on the determinant, $\operatorname{Det}\left(J_{s s}\right)$, of the matrix $J_{s s}$,

$$
\operatorname{Det}\left(J_{s s}\right) \in\left(\operatorname{Tr}\left(J_{s s}\right)-1, \frac{\operatorname{Tr}\left(J_{s s}\right)^{2}}{4}\right),
$$

where the (open) upper bound on the determinant rules out the steady state as being either a spiral sink or a spiral source, and the (open) lower bound rules out the steady state as being either a saddle or an unstable node. In this regard, observe first that (29) yields

$$
\operatorname{Det}\left(J_{s s}\right)=\alpha\{1-\omega(1-\beta)\}-(1-\alpha) \lambda \omega \text {. }
$$


To verify the upper bound in (31) using (30) and (32), notice that

$$
4 \operatorname{Det}\left(J_{s s}\right)<\operatorname{Tr}\left(J_{s s}\right)^{2} \Leftrightarrow-4(1-\alpha) \lambda \omega<[1-\omega(1-\beta)-\alpha]^{2},
$$

where the inequality always holds for any $\omega$ since $(1-\alpha) \lambda \omega>0, \forall \omega \in(0,1)$. To verify the lower bound in (31) using (30) and (32), notice that

$$
\operatorname{Det}\left(J_{s s}\right)>\operatorname{Tr}\left(J_{s s}\right)-1 \Leftrightarrow(1-\alpha) \omega(1-\beta-\lambda)>0,
$$

where, again, the inequality always holds under (A2) for any $\omega \in(0,1)$, which completes the part of the proof that $\left(A_{s s}^{R}, L_{s s}\right)$ is a locally asymptotically stable node of the conditional dynamical system comprised of (17) and (18).

To establish the necessary and sufficient condition for the local monotonic evolution of the state variables, recall that such a condition must be necessary and sufficient to ensure that the eigenvalues of $J_{s s}$ are both real and positive. The fact that the steady state is neither a spiral sink nor a spiral source ensures that the eigenvalues of $J_{s s}$ are indeed real. Moreover, it follows from (30) that, under (A2), at least one of the eigenvalues must be positive. Therefore, the condition reduces to one that is necessary and sufficient to ensure that (32) is positive. Specifically,

$$
\operatorname{Det}\left(J_{s s}\right)>0 \Leftrightarrow \frac{\alpha}{\alpha(1-\lambda-\beta)+\lambda}>\omega,
$$

where the last inequality is precisely the condition specified in Lemma 8 for the monotonic evolution of the state variables, thereby, completing the proof.

Proof of Lemma 10. For the first part of the lemma, it follows directly from (26) that

$$
g_{s s}(\omega) \gtreqless 0 \Leftrightarrow \omega \lesseqgtr 1-\left(\frac{\tau}{1-\gamma}\right)^{\frac{\lambda}{1-\alpha}} \equiv \hat{\omega},
$$

where $\hat{\omega} \in(0,1)$ under assumption (A4).

For the sign of the derivative at 0 in the second part of the lemma, differentiating $g_{s s}$, as specified in (26), with respect to $\omega$ yields, upon algebraic simplification,

$$
\frac{d g_{s s}(\omega)}{d \omega}=\left[\left(\frac{1-\gamma}{\tau}\right)^{\frac{1-\beta}{1-\alpha}}(1-\omega)\right]^{\frac{\lambda}{1-\lambda-\beta}}\left[1-\left(\frac{2-\lambda-2 \beta}{1-\lambda-\beta}\right) \omega\right]-1
$$

which, when evaluated at $\omega=0$, reduces to

$$
\frac{d g_{s s}(0)}{d \omega}=\left(\frac{1-\gamma}{\tau}\right)^{\frac{1-\beta}{1-\alpha} \frac{\lambda}{1-\lambda-\beta}}-1>0
$$

where the positivity follows from assumptions (A2) and (A4). To derive the inflection point, twice 
differentiating $g_{s s}$ with respect to $\omega$ yields, upon algebraic simplification,

$$
\frac{d^{2} g_{s s}(\omega)}{(d \omega)^{2}}=-\left[\left(\frac{1-\gamma}{\tau}\right)^{\frac{1-\beta}{1-\alpha}}(1-\omega)\right]^{\frac{\lambda}{1-\lambda-\beta}} \frac{(1-\beta)[(2-\lambda-2 \beta)(1-\omega)-\lambda]}{(1-\omega)(1-\lambda-\beta)^{2}}
$$

It then follows immediately from (35) that

$$
\frac{d^{2} g_{s s}(\omega)}{(d \omega)^{2}} \gtreqless 0 \Leftrightarrow \omega \gtreqless \frac{2(1-\lambda-\beta)}{2-\lambda-2 \beta} \equiv \tilde{\omega},
$$

where, under (A2), $\tilde{\omega} \in(0,1)$. Moreover, noting $\tilde{\omega}$ above, evaluating (33) at $\omega=\tilde{\omega}$ yields

$$
\frac{d g_{s s}(\tilde{\omega})}{d \omega}=-\left[\left(\frac{1-\gamma}{\tau}\right)^{\frac{1-\beta}{1-\alpha}}\left(\frac{\lambda}{2-\lambda-2 \beta}\right)\right]^{\frac{\lambda}{1-\lambda-\beta}}-1<0,
$$

where the negativity follows directly from (A2) and (A4), thereby, completing the proof.

\section{References}

Abu-Lughod, J. L. (1989): Before European Hegemony: The World System A.D. 1250-1350. Oxford University Press, New York, NY.

Acemoglu, D., S. Johnson, and J. A. Robinson (2001): "The Colonial Origins of Comparative Development: An Empirical Investigation," American Economic Review, 91(5), 1369-1401.

(2002): "Reversal of Fortune: Geography and Institutions in the Making of the Modern World Income Distribution," Quarterly Journal of Economics, 117(4), 1231-1294.

Alesina, A., Et AL. (2003): "Fractionalization," Journal of Economic Growth, 8(2), 155-194.

Alesina, A., and E. La Ferrara (2005): "Ethnic Diversity and Economic Performance," Journal of Economic Literature, 43(3), 762-800.

ArIeti, S. (1976): Creativity: The Magic Synthesis. Basic Books, New York, NY.

Ashtor, E. (1973): The Jews of Moslem Spain, Vol. 1. Translated by A. Klein and J. M. Klein. Jewish Publication Society of America, Philadelphia, PA.

BanerJee, A., And L. Iyer (2005): "History, Institutions, and Economic Performance: The Legacy of Colonial Land Tenure Systems in India," American Economic Review, 95(4), 11901213.

Barro, R. J., and R. M. McCleary (2003): "Religion and Economic Growth across Countries," American Sociological Review, 68(5), 760-781. 
Berliant, M., and M. Fujita (2006): "Knowledge Creation as a Square Dance on the Hilbert Cube," Working Paper, Department of Economics, Washington University in St. Louis.

Bertocchi, G., and F. Canova (2002): "Did Colonization Matter for Growth? An Empirical Exploration into the Historical Causes of Africa's Underdevelopment," European Economic Review, 46(10), 1851-1871.

Bisin, A., And T. Verdier (2000): "Beyond the Melting Pot: Cultural Transmission, Marriage, and the Evolution of Ethnic and Religious Traits," Quarterly Journal of Economics, 115(3), 955-988.

- (2001): "The Economics of Cultural Transmission and the Dynamics of Preferences," Journal of Economic Theory, 97(2), 298-319.

Botticini, M., And Z. Eckstein (2006): "From Farmers to Merchants, Voluntary Conversions and Diaspora: A Human Capital Interpretation of Jewish History," CEPR Discussion Paper No. 5571.

Bowles, S. (1998): "Endogenous Preferences: The Cultural Consequences of Markets and Other Economic Institutions," Journal of Economic Literature, 36(1), 75-111.

Boyd, R., And P. J. Richerson (1985): Culture and the Evolutionary Process. University of Chicago Press, Chicago, IL.

Brezis, E. S., P. R. Krugman, and D. Tsiddon (1993): "Leapfrogging in International Competition: A Theory of Cycles in National Technological Leadership," American Economic Review, 83(5), 1211-1219.

Cavalli-Sforza, L. L., and M. W. Feldman (1981): Cultural Transmission and Evolution: A Quantitative Approach. Princeton University Press, Princeton, NJ.

Chaudhuri, K. N. (1990): Asia before Europe: Economy and Civilization of the Indian Ocean from the Rise of Islam to 1750. Cambridge University Press, Cambridge, UK.

Ch'en, K. K. S. (1964): Buddhism in China: A Historical Survey. Princeton University Press, Princeton, NJ.

Chow, K. (1994): The Rise of Confucian Ritualism in Late Imperial China: Ethics, Classics, and Lineage Discourse. Stanford University Press, Stanford, CA.

Collier, P. (2000): "Ethnicity, Politics and Economic Performance," Economics and Politics, $12(3), 225-245$.

(2001): "Implications of Ethnic Diversity," Economic Policy, 32(16), 127-166. 
Collier, P., And J. W. Gunning (1999): "Explaining African Economic Performance," Journal of Economic Literature, 37(1), 64-111.

Cressey, G. B. (1934): China's Geographic Foundations: A Survey of the Land and Its People. McGraw-Hill Book Co., New York, NY.

Deng, G. (1993): Development Versus Stagnation: Technological Continuity and Agricultural Progress in Pre-modern China. Greenwood Press, Westport, CT.

Diamond, J. (1997): Guns, Germs and Steel: The Fates of Human Societies. W. W. Norton \& Co., New York, NY.

Doepke, M. (2004): "Accounting for Fertility Decline During the Transition to Growth," Journal of Economic Growth, 9(3), 347-383.

Doepke, M., and F. Zilibotti (2005a): "Social Class and the Spirit of Capitalism," Journal of the European Economic Association, 3(2-3), 516-524.

- (2005b): "Patience Capital, Occupational Choice, and the Spirit of Capitalism," Working Paper, Department of Economics, UCLA.

Easterly, W. (2001): "Can Institutions Resolve Ethnic Conflict?," Economic Development and Cultural Change, 49(4), 687-706.

Easterly, W., And R. Levine (1997): “Africa's Growth Tragedy: Policies and Ethnic Divisions," Quarterly Journal of Economics, 112(4), 1203-1250.

— (2003): "Tropics, Germs and Crops: How Endowments Influence Economic Development," Journal of Monetary Economics, 50(1), 3-39.

Elman, B. A. (2000): A Cultural History of Civil Examinations in Late Imperial China. University of California Press, Berkeley, CA.

Elvin, M. (1973): The Pattern of the Chinese Past. Stanford University Press, Stanford, CA.

Engerman, S. L., and K. L. Sokoloff (2000): "History Lessons: Institutions, Factor Endowments, and Paths of Development in the New World," Journal of Economic Perspectives, 14(3), $217-232$.

Fairbank, J. K. (1992): China: A New History. Bellknap Press of Harvard University Press, Cambridge, MA.

Fernández-Villaverde, J. (2001): "Was Malthus Right? Economic Growth and Population Dynamics," Working Paper, Department of Economics, University of Pennsylvania. 
Frank, A. G. (1998): Re-Orient: Global Economy in the Asian Age. University of California Press, Berkeley, CA.

Funuyama, F. (1995): Trust: The Social Virtues and The Creation of Prosperity. Free Press, New York, NY.

Gallup, J. L., J. D. Sachs, and A. D. Mellinger (1999): "Geography and Economic Development," International Regional Science Review, 22(2), 179-232.

Galor, O. (2005): "From Stagnation to Growth: Unified Growth Theory," in Handbook of Economic Growth, Vol IA, ed. by P. Aghion, and S. N. Durlauf. Elsevier North-Holland, Amsterdam, The Netherlands.

(2007): Discrete Dynamical Systems. Springer, Berlin, Germany.

Galor, O., and S. Michalopoulos (2006): "The Evolution of Entrepreneurial Spirit and the Process of Development," Working Paper, Department of Economics, Brown University.

Galor, O., And O. Moav (2002): "Natural Selection and the Origin of Economic Growth," Quarterly Journal of Economics, 117(4), 1133-1191.

Galor, O., O. Moav, and D. Vollrath (2006): "Inequality in Land Ownership, the Emergence of Human Capital Promoting Institutions, and the Great Divergence," Working Paper, Department of Economics, Brown University.

Galor, O., and A. Mountford (2004): "Trading Population for Productivity," Working Paper, Department of Economics, Brown University.

- (2006): "Trade and the Great Divergence: The Family Connection," American Economic Review, 96(2), 299-303.

Galor, O., And D. N. Weil (2000): "Population, Technology, and Growth: From Malthusian Stagnation to the Demographic Transition and Beyond," American Economic Review, 90(4), 806-828.

Gernet, J. (1982): A History of Chinese Civilization. Translated by J. R. Foster. Cambridge University Press, New York, NY.

Glaeser, E. L., Et AL. (2004): "Do Institutions Cause Growth?," Journal of Economic Growth, $9(3), 271-303$.

Goody, J. (1996): The East in the West. Cambridge University Press, Cambridge, UK.

Gradstein, M., and M. Justman (2002): "Education, Social Cohesion, and Economic Growth," American Economic Review, 92(4), 1192-1204. 
Greif, A. (1993): "Contract Enforceability and Economic Institutions in Early Trade: The Maghribi Traders' Coalition," American Economic Review, 83(3), 525-548.

(1994): "Cultural Beliefs and the Organization of Society: A Historical and Theoretical Reflection on Collectivist and Individualist Societies," Journal of Political Economy, 102(5), 912-950.

Guiso, L., P. Sapienza, and L. Zingales (2003): "People's Opium? Religion and Economic Attitudes," Journal of Monetary Economics, 50(1), 225-282.

- (2006): "Does Culture Affect Economic Outcomes?," Journal of Economic Perspectives, $20(2), 23-48$.

Hall, J. A. (1986): Powers and Liberties: The Causes and Consequences of the Rise of the West. University of California Press, Berkeley, CA.

Harrington, Jr., J. E. (1998): "The Social Selection of Flexible and Rigid Agents," American Economic Review, 88(1), 63-82.

— (1999): "Rigidity of Social Systems," Journal of Political Economy, 107(1), 40-64.

Heiner, R. A. (1983): "The Origin of Predictable Behavior," American Economic Review, 73(4), $560-595$.

Ho, P. (1967): "The Significance of the Ch'ing Period in Chinese History," Journal of Asian Studies, 26(2), 189-195.

Hobson, J. M. (2004): The Eastern Origins of Western Civilization. Cambridge University Press, Cambridge, UK.

Hong, L., And S. E. Page (2001): "Problem Solving by Heterogeneous Agents," Journal of Economic Theory, 97(1), 123-163.

Jones, E. L. (1981): The European Miracle: Environments, Economies and Geopolitics in the History of Europe and Asia. Cambridge University Press, Cambridge, UK.

Kandori, M. (1992): "Social Norms and Community Enforcement," Review of Economic Studies, $59(1), 63-80$.

Knack, S., and P. Keefer (1997): "Does Social Capital Have an Economic Payoff? A CrossCountry Investigation," Quarterly Journal of Economics, 112(4), 1251-1288.

LagerlöF, N.-P. (2003): "From Malthus to Modern Growth: Can Epidemics Explain the Three Regimes?," International Economic Review, 44(2), 755-777. 
- (2006): "The Galor-Weil Model Revisited: A Quantitative Exercise," Review of Economic Dynamics, 9(1), 116-142.

LAL, D. (1998): Unintended Consequences: The Impact of Factor Endowments, Culture and Politics on Long-Run Economic Performance. The MIT Press, Cambridge, MA.

Landes, D. S. (1998): The Wealth and Poverty of Nations: Why Some Are So Rich and Some So Poor. W. W. Norton \& Co., New York, NY.

- (2006): "Why Europe and the West? Why Not China?," Journal of Economic Perspectives, 20(2), 3-22.

LAZEAR, E. P. (1999a): "Culture and Language," Journal of Political Economy, 107(6-2), S95S126.

- (1999b): "Globalisation and the Market for Team-Mates," Economic Journal, 109(454), C15-C40.

Lester, A. (2006): "Inequality and the Dual Economy: Technology Adoption with Specific and General Skills," Working Paper, Department of Economics, Brown University.

Lian, B., and J. R. Oneal (1997): "Cultural Diversity and Economic Development: A CrossNational Study of 98 Countries, 1960-1985," Economic Development and Cultural Change, 46(1), $61-77$.

LuCAS, JR., R. E. (2002): "The Industrial Revolution: Past and Future," in Lectures on Economic Growth, ed. by R. E. Lucas, Jr. Harvard University Press, Cambridge, MA.

Maddison, A. (2001): The World Economy: A Millennial Perspective. OECD, Paris.

McEvedy, C., and R. Jones (1978): Atlas of World Population History. Penguin Books Ltd., New York, NY.

McNeILl, W. H. (1963): The Rise of the West: A History of the Human Community. University of Chicago Press, Chicago, IL.

Mokyr, J. (1990): The Lever of Riches: Technological Creativity and Economic Progress. Oxford University Press, New York, NY.

- (2002): The Gifts of Athena: Historical Origins of the Knowledge Economy. Princeton University Press, Princeton, NJ.

Montalvo, J. G., and M. Reynal-Querol (2005): "Ethnic Diversity and Economic Development," Journal of Development Economics, 76(2), 293-323.

NAsR, S. H. (1968): Science and Civilization in Islam. Harvard University Press, Cambridge, MA. 
Needham, J. (1956): Science and Civilisation in China, Vol. II. Cambridge University Press, New York, NY.

Needham, J., and F. Bray (1984): Science and Civilisation in China, Vol. VI:2. Cambridge University Press, New York, NY.

Needham, J., and T. Tsuen-Hsuin (1985): Science and Civilisation in China, Vol. V:1. Cambridge University Press, New York, NY.

North, D. C. (1981): Structure and Change in Economic History. W. W. Norton \& Co., New York, NY.

(1991): "Institutions," Journal of Economic Perspectives, 5(1), 97-112.

North, D. C., and R. P. Thomas (1973): The Rise of the Western World: A New Economic History. Cambridge University Press, Cambridge, UK.

Olsson, O., And D. A. HibBs, JR. (2005): "Biogeography and Long-Run Economic Development," European Economic Review, 49(4), 909-938.

Ottaviano, G. I. P., and G. Peri (2005): "Cities and Cultures," Journal of Urban Economics, $58(2), 304-337$.

- (2006): "The Economic Value of Cultural Diversity: Evidence from U.S. Cities," Journal of Economic Geography, 6(1), 9-44.

Pomeranz, K. (2000): The Great Divergence: Europe, China and the Making of the Modern World Economy. Princeton University Press, Princeton, NJ.

Prat, A. (2002): "Should a Team be Homogenous?," European Economic Review, 46(7), 11871207.

Rodrik, D., A. Subramanian, and F. Trebbi (2004): "Institutions Rule: The Primacy of Institutions Over Geography and Integration in Economic Development," Journal of Economic Growth, 9(2), 131-165.

Sarton, G. (1927): Introduction to the History of Science, Vol. I: From Homer to Omar Khayyam. Williams \& Wilkins Co., Baltimore, MD.

- (1931): Introduction to the History of Science, Vol. II: From Rabbi Ben Ezra to Roger Bacon. Williams \& Wilkins Co., Baltimore, MD.

Scoville, W. C. (1951): "Spread of Techniques: Minority Migrations and the Diffusion of Technology," Journal of Economic History, 11(4), 347-360. 
Simonton, D. K. (1997): "Foreign Influence and National Achievement: The Impact of Open Milieus on Japanese Civilization," Journal of Personality and Social Psychology, 72(1), 86-94.

(2004): "Creative Clusters, Political Fragmentation and Cultural Heterogeneity: An Investigative Journey through Civilizations East and West," in Political Competition, Innovation and Growth in the History of Asian Civilizations, ed. by P. Bernholz, and R. Vaubel. Edward Elgar Publishing Ltd., Cheltenham, UK.

Sorokin, P. A. (1947): Society, Culture, and Personality: Their Structure and Dynamics. Harper \& Brothers, New York, NY.

Spolaore, E., and R. Wacziarg (2006): "The Diffusion of Development," CEPR Discussion Paper No. 5630.

Tabellini, G. (2005): "Culture and Institutions: Economic Development in the Regions of Europe," CESifo Working Paper No. 1492.

Temple, J., And P. A. Johnson (1998): "Social Capability and Economic Growth," Quarterly Journal of Economics, 113(3), 965-990.

Toynbee, A. J. (1957): A Study of History. Abridgement of Vols. VII-X by D. C. Somervell. Oxford University Press, Oxford, UK.

Voigtländer, N., And H.-J. Voth (2006): "Why England? Demographic Factors, Structural Change and Physical Capital Accumulation During the Industrial Revolution," Journal of Economic Growth, 11(4), 319-361.

Weber, M. (1905): The Protestant Ethic and the Spirit of Capitalism. Translated by T. Parsons, and A. Giddens, 1930. Allen \& Unwin, London, UK.

- (1922): The Religion of China: Confucianism and Taoism. Translated and edited by H. H. Gerth, 1951. Free Press, Glencoe, IL.

Wong, R. B. (1997): China Transformed: Historical Change and the Limits of European Experience. Cornell University Press, Ithaca, NY.

ZaK, P. J., And S. Knack (2001): "Trust and Growth," Economic Journal, 111(470), 295-321. 